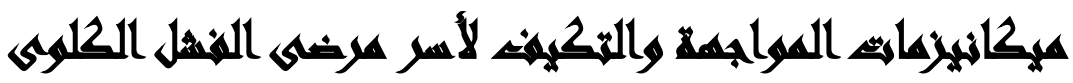

[11]

\author{
أحمد مصطفى العتيق(')- أحمد عصمت شومان(ץ)- أحمد فخري هاني(')

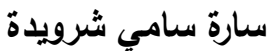

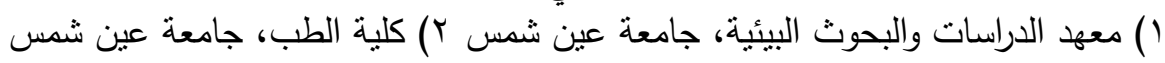

\section{المستخليه}

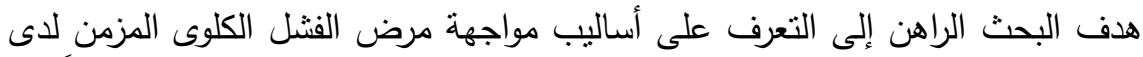

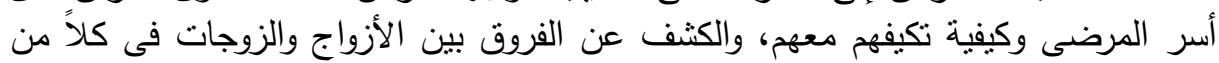

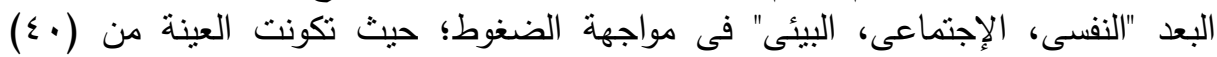

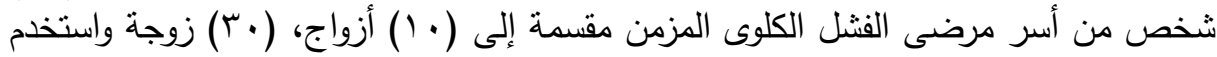

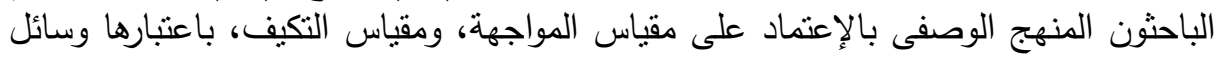

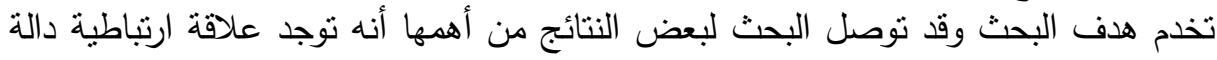

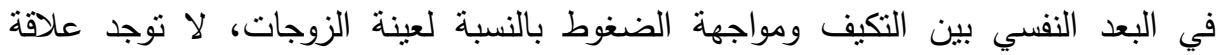

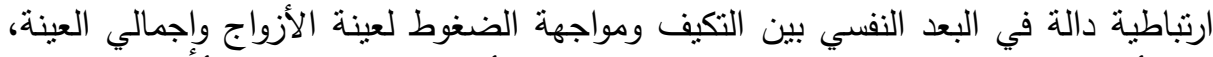

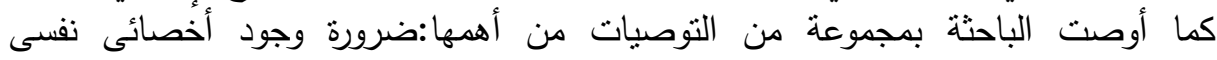

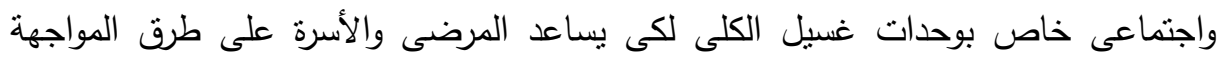

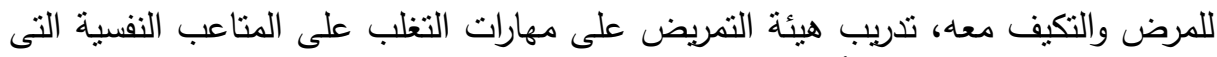

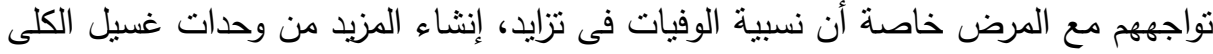

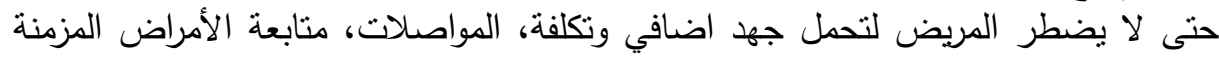
النى تؤدى إلى الفشل الكلوى.

\section{8avodl}

إن الإنسان بطبيعته يشعر بالألم والأوجاع عندما يشاهد شخص يتوجع بسبب مرض الفار

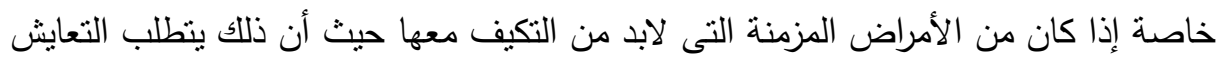

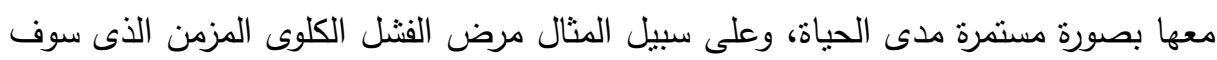

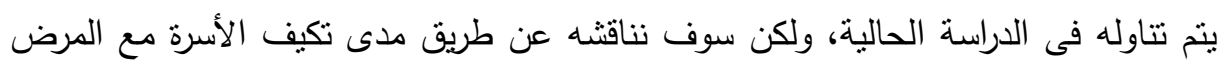
فهذا المرض طريقة علاجه التى تعتبر من أقصى الصعوبات التى نواجه المريض والأسرة، وهى تكون عن طريق غسيل الكلى حيث يحدث تغير فى جميع نواحى الحياة "النفسية

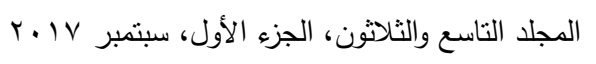


والإجتماعية والبيئية والإقتصادية" والتى يجب على الجميع تقبلها والتعايش معها لأنها مسمترة

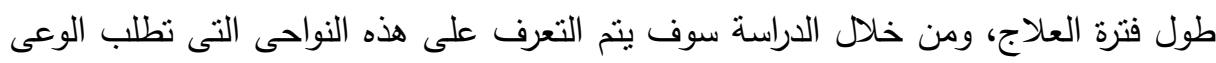
لكى تتخطى الأسرة الحالة الجديدة التى تتعايش معها.

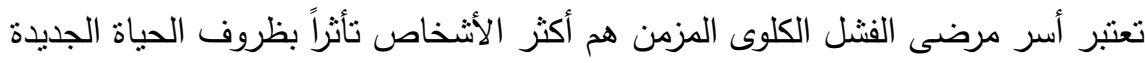
التى تحدث نتيجة لطريقة العلاج المستمرة للمريض والمرافق له حيث أن ظروف بيئية مختلفة عن نمط حياتهم السابقة، وهذا بسبب ظروف العلاج حيث يكون نواجدهم فى البيئة العلاجية

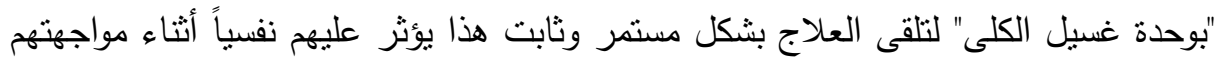

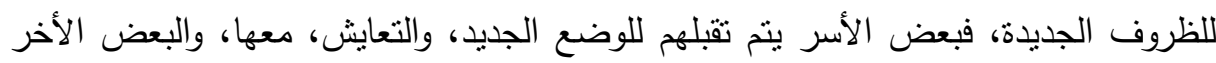

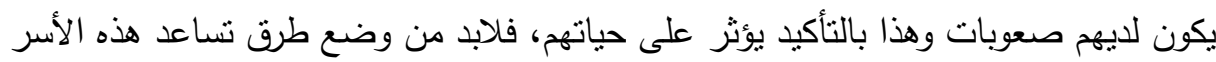
فى مواجهة هذا المرض، وأسلوب علاجه والتغيرات الجديدة التى تؤثر على على حياتهم. يرى "موس"و "ثيفر"(Moos\&Schaefer) (1993) أن المواجهة هى "أساليب شعورية

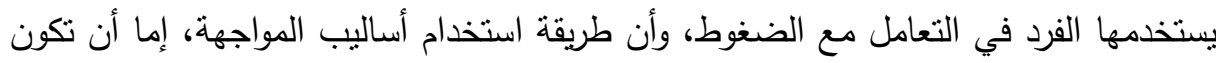
إقدامية أو إحجامية، وأن لهذه الأساليب الإقدامية والإحجامية جانبين أحدهما معرفى والآخر سلوكى، ومن ثم يكون أسلوب الفرد وطريقته في مواجهة المواقف الضاغطة إقدامياً معرفياً أو الإن الإنها

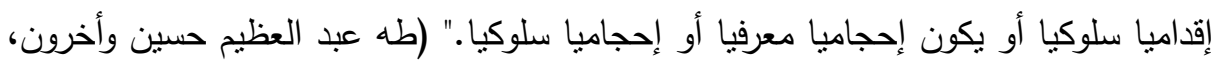

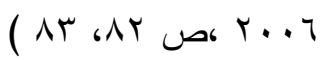

\section{And ILax}

يتسبب المرض فى أن يفقد الإنسان صحته نتيجة قصور عضو أو أكثر من أعضاء الجسم، وهذا عن طريق نوقفه بوظيفته إتجاه الجسم، والفثل الكلوى المزمن يكون من أكثر

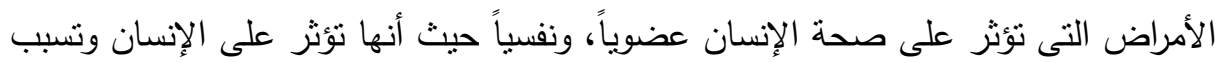

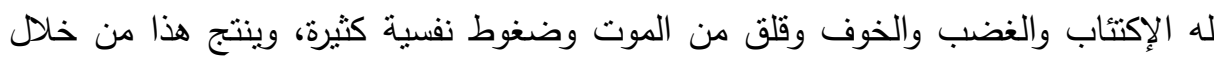
طرق العلاج القوية التى يتعالج بها المريض، حيث يتم عن طريق غسيل الكلى. 
فلأسرة دور فى النمو النفسى لأى شخص داخلها وخاصة المريض ،فهى التى تساعده

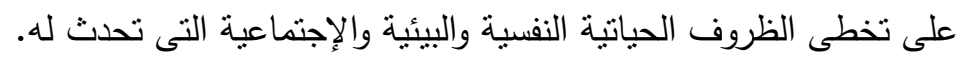

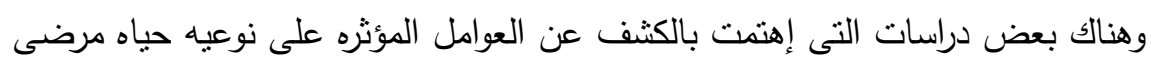

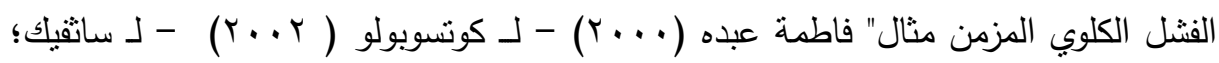

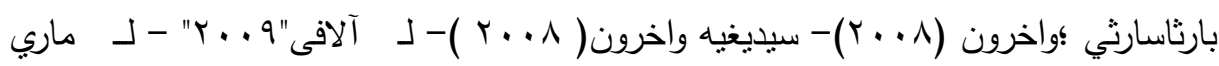

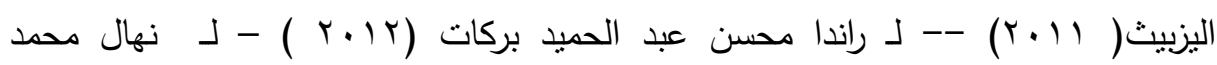

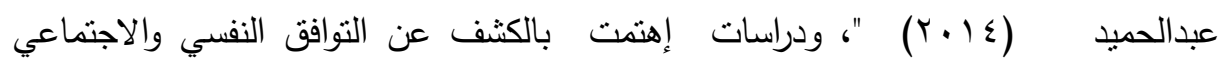
والمشكلات التى تواجههم ومن هذه الدراسات ما يلي: " لـ حسين محمد محمد توفيق

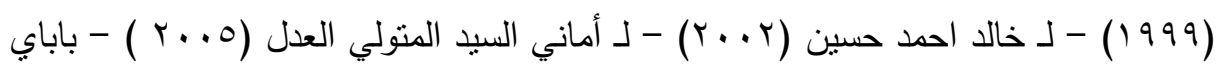

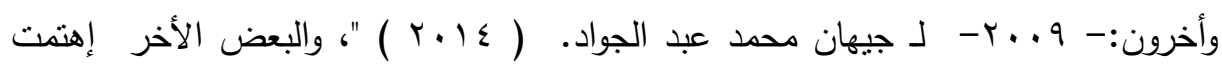

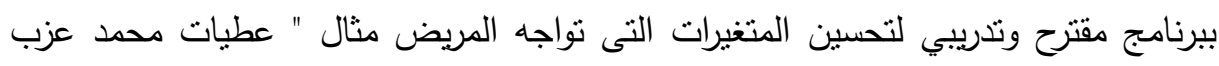

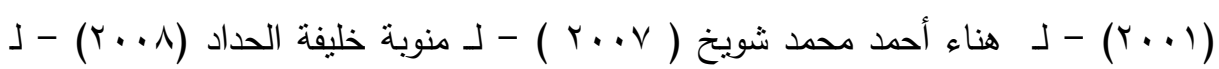

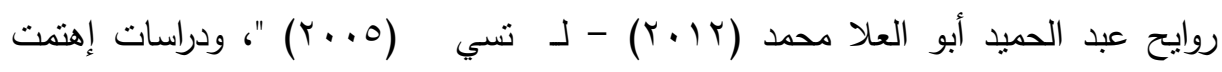

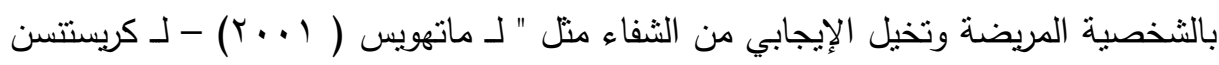

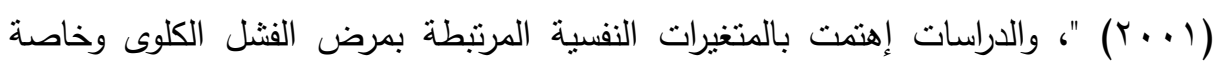

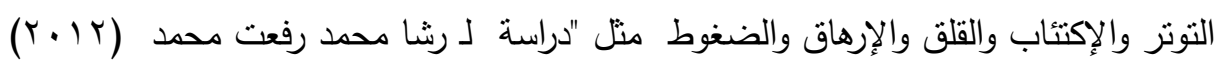

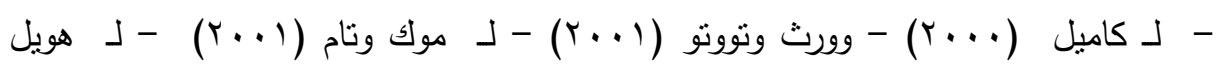

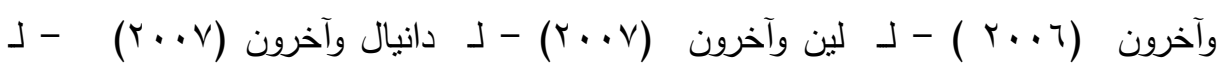

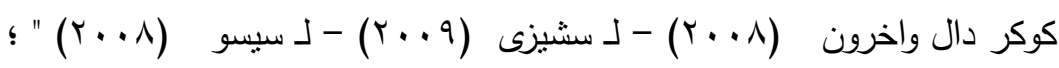
وبعد الاطلاع على هذه الدراسات السابقة قام الباحثون بوضع خطة بحثية لهذا الموضوع

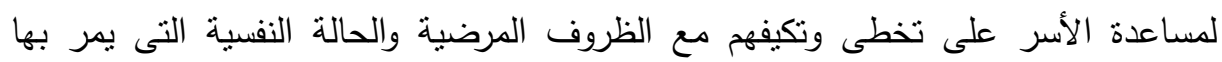

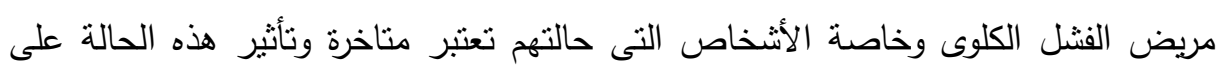

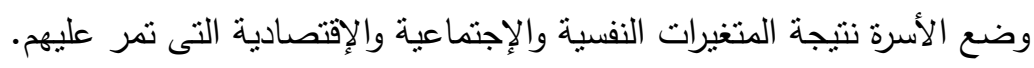


ولهذا يعد للبحث الحالى مشكلة راهنه نواجه المجتمع بأكمله حيث يتضح بعد الإطلاع

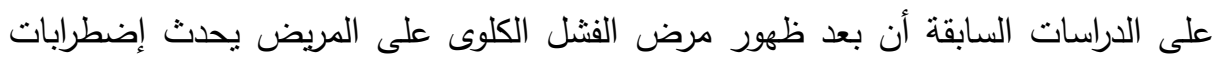

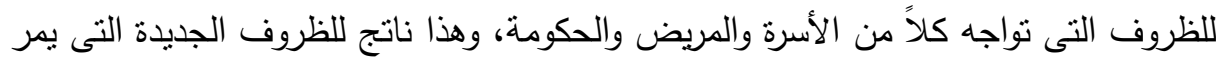
بها المرض والأسرة من الحالة الإقتصادية والإجتماعية والنفسية وهذا ما سوف يقوم ولهن الباحثنون بوضع طرق لمواجهة هذه الظروف ومساعدة الأسرة على التكيف مع المرض والمريض.

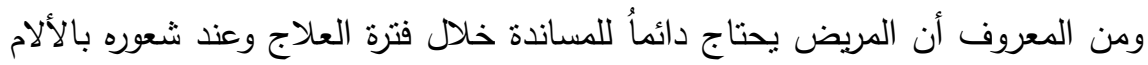
فلهذا يحتاج أكثر لوجود علاج أسرى لكى يساعده على تخطيه الحالة النفسية التى يعيش فيها دائماً، ولذلك إن العلاج الأسرى كمدرسة علاجية أصبح لهاج أسسها النظرية وترتيباتها

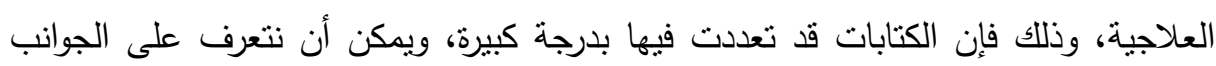
الآتية في هذه المدرسة؛ حيث أن للعلاج الأسرى مميزات كثثرة منها:

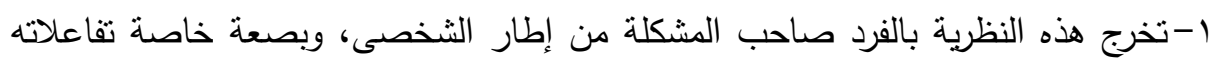
الدخلية وإستقباله لخبراته إلى اعتباره فرداً في المنظومة، وجزء من من علاقات الفات وجانباً في بناء. r-العودة إلى منظومة الأسرة مع تغير شخصى يؤدى إلى انتكاسة في الحالة، والعودة إلى المرض ما لم يكن هناك علاج للمنظومة كلها. r-على الرغم من إدراك كثير من أصحاب نظريات العلاج النفسي إلى الدور الذى تلعبه الأسرة في نمو شخصية الطفل بل، وإنتاجها للسلوك الذى يقوم به سواء السلوك الصحيح

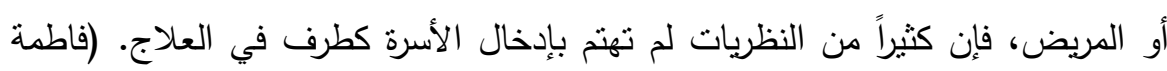

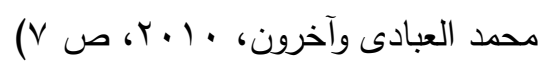

\section{أسهرلج المهيم}

1. ما العلاقة بين في البعد النفسي بين التكيف ومواجهة الضغوط؟

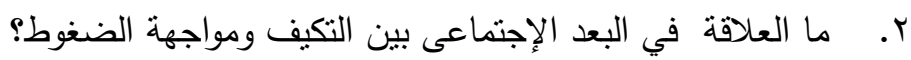


r. ما مدى وجود فروق بين الأزواج والزوجات فى الميكانيزم النفسى والاجنماعى والبيئى

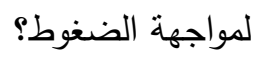

\section{أهمية المهيث}

ا. يهتم الباحثون بتوضيح المشكلات النفسية والإجتماعية والبيئية المرتبطة بأسر مرضى

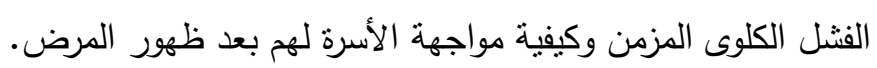

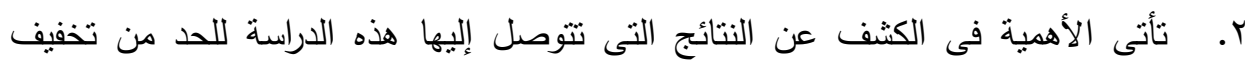
المشكلات التى تواجه أسر مرضى الفنل الكلوى المزمن أثناء العلاج.

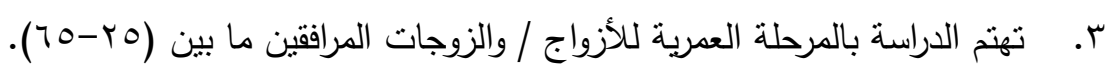

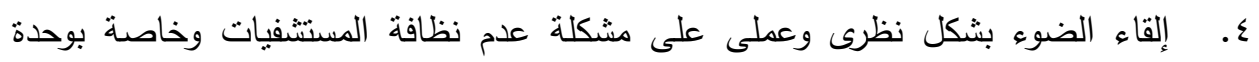
الغسيل الكلوى وهذا الذى لاحظ فى بعض المستشفيات التى فيها إجراء العينة.

\section{أهسا اهن المهنه}

$$
\text { تثقسم أهداف البحث إلى: }
$$

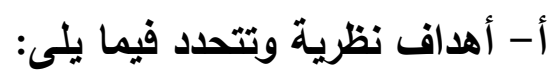

1-الكثف عن مرض الفنل الكلوى وكيفية إكتثافه مبكراً حتى لا يصل المريض لحالة

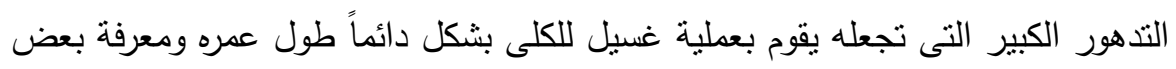
الأمراض الناتجة عن هذا المرض. ץ-التعرف على المشكلة المرضية وخاصة إذا كانت من الأمراض المزمنة "كمرض الفنشل

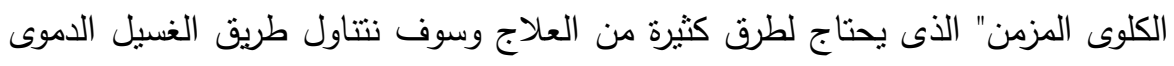

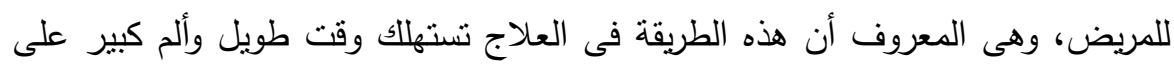
المريض والمرافق فلهذا نحاول من خلال الدراسة الكثف عن الصعوبات التى تواجههم وطرق تكيفهم وتقبلهم للوضع الجديد. ب-التعرف على أساليب مواجهة مرض الفتل الكلوى المزمن لدى أسر المرضي وكيفية تكيفهر معه. 


\section{ب - أهداف عملية وتتحدد فيما يلى:}

- الكثف عن الفروق بين الأزواج والزوجات فى كلاً من البعد "النفسى - الإجتماعى ل البيئى" فى مواجهة الضغوط.

- توضيح الفروق بين مواجهة "زوج / زوجة" المرافق للمريض فى مواجهة المشكلات الطارئة عليهم بعد ظهور المرض. - مان. - النواصل لأنسب حلول لمحاولة المواجهة والنوافق "النفسى والإجتماعى " أو التكيف للأسرة والمريض مع المشكلات البيئية المصاحبة لطرق علاج مرض الفشل الكلوى المزمن.

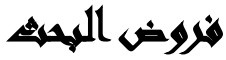

• توجد علاقة ارتباطية دالة في البعد النفسي بين التكيف ومواجهة الضغوط.

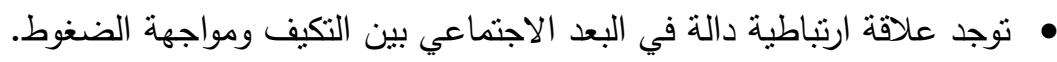

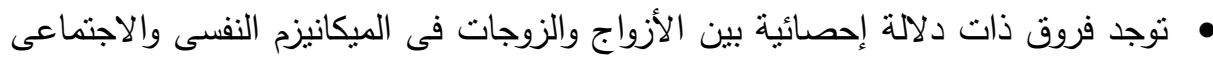
والبيئى لمواجهة الضغوط.

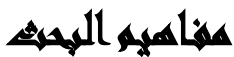

الميكانيزمات: هى كلمة فرنسية أصلها لاتينى " Mecanismes" وتعنى ترتيب أجزاء لإحداث حركة أو تأثثر معين مثل آلية الساعة أو الطريقة التى ترتب بها أجزاء كلمة أو جملة

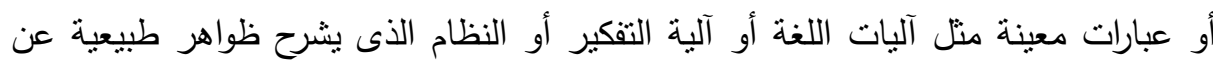

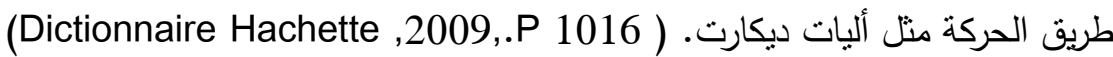
مفهوم المواجهة: يعرفها لطفى بأنها مجموع الأليات التى إستخدها الفرد للتوافق مع

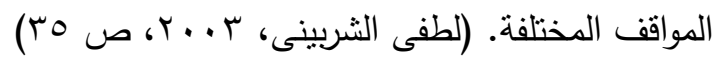
المواجهة هى "أساليب شعورية يستخدمها الفرد في التعامل مع الضغوط، وأن طريقة إستخدام أساليب المواجهة، إما أن تكون إقدامية أو إحجامية، وأن لهذه الأساليب الإقدامية

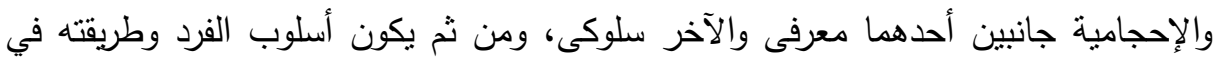


مواجهة المواقف الضاغطة إقدامياً معرفياً أو إقداميا سلوكيا أو يكون إحجاميا معرفيا أو

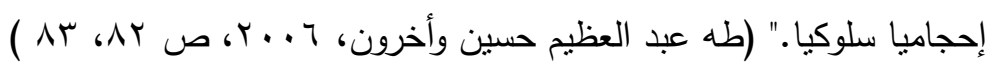

مفهوم التكيف: مصطلح التكيف مرتبط بعلم الحياة بدل على تغير فى الكائن الحى سواء أكان فى البناء أم فى الوظيفة يجعله أكثر قدرة على المحافظة على حياته أو على أبناء جنسه، وإستخدام المصطلح فى علم النفس الإجتماعى ليثير إلى تغيير سلوك الفرد لكى يتفق

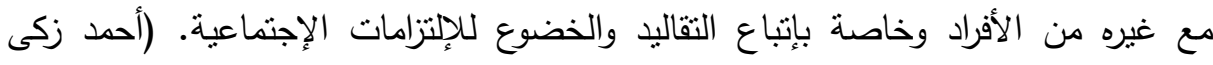

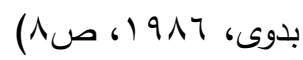
مفهوم الأسرة: مجموعة الأفراد الذين يرنبطون مع بعضهم البعض بروابط الدم والمشاركة في السكن وهى تعني كذلك: مجموعة المكونات والأدوار المكتسبة عن طريق الزواج والأولاد.

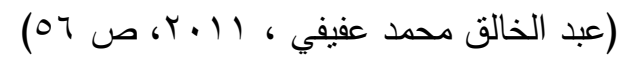
مرض الفشل الكلوى: يوصف الفثل الكلوى بأنه إنخفاض في معدل الترشيح ، حيث

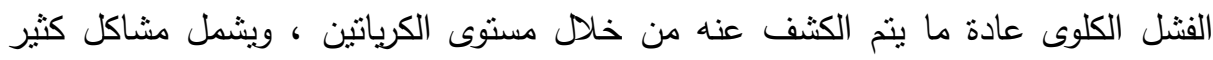
تصادف فى القصور الكلوي حيث السؤال غير الطبيعة والمسنويات غير عادية من البوتاسيوم

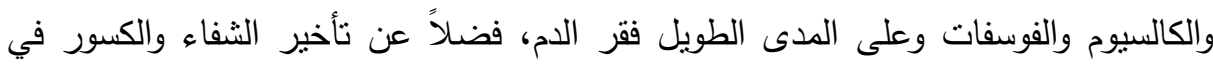

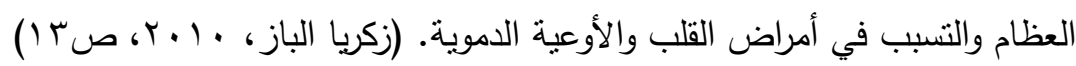

\section{السراسايت السابرية}

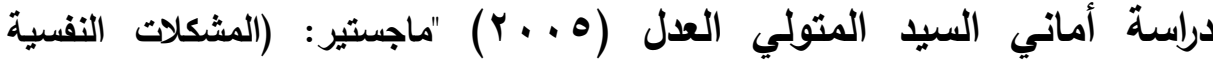

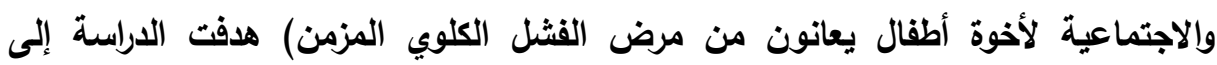

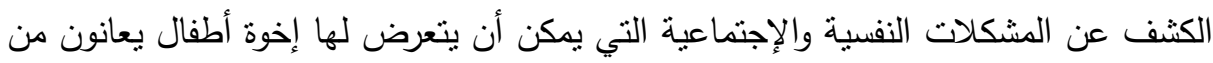

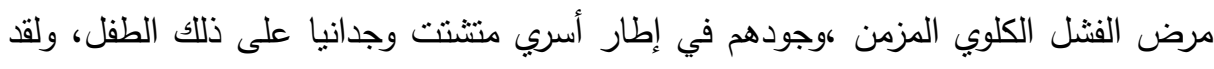
إختارت الباحثة عينة من الأطفال وعددهم (•^) طفلا وطفلة منمثلة في مجموعتين، المجموعة الأولى متمنلة في (• (ـ) طفلا وطفلة لإخوة أطفال يعانون من مرض الفنشل الكلوي

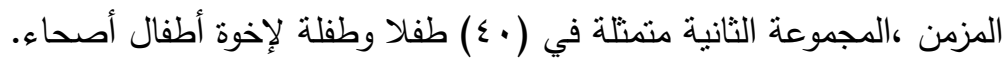

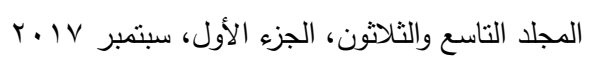


• مستوى الإكتئاب، القلق، الخوف، الغيرة، الدرجة الكلية للمشكلات النفسية والإجتماعية للاكور إخوة الأطفال المرضى بالفشل الكلوي المزمن تقترب من درجة الوسيط للمقياس.

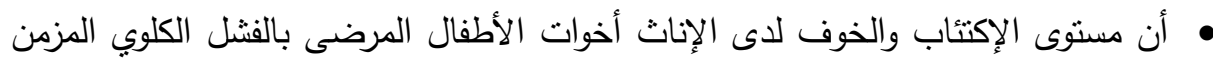
أعلى من درجة الوسيط ، وأن مستوى القلق والغيرة لديهم تقترب من الوسيط للمقياس.

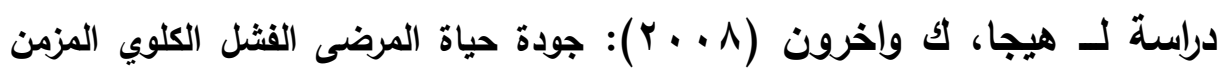
والخاضع لعلاج الغسيل الكلوى، هدفت الدراسة إلى تحليل نوعية الحياة لمرضي القصور

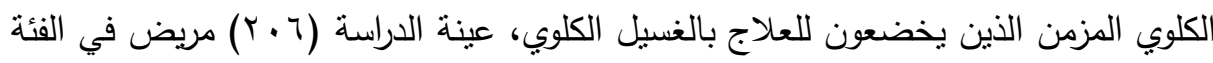

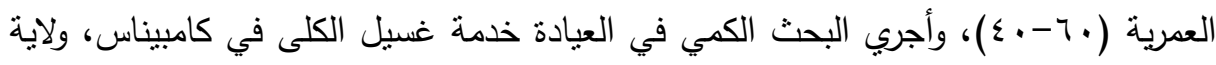

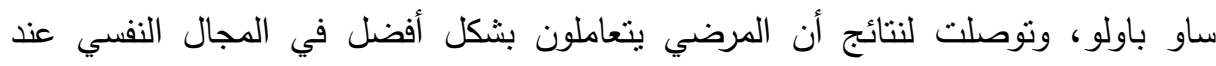

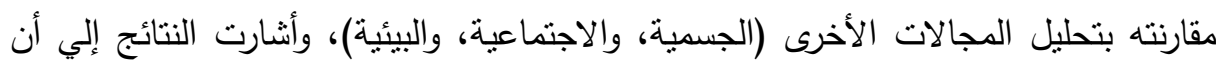

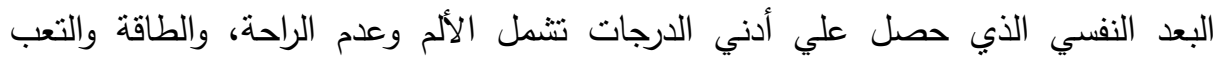

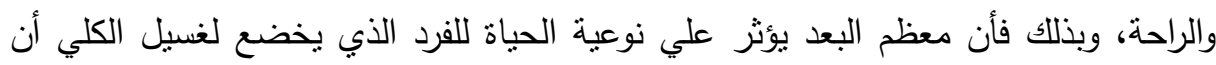

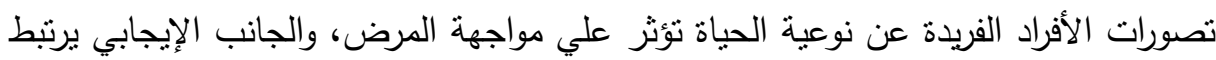

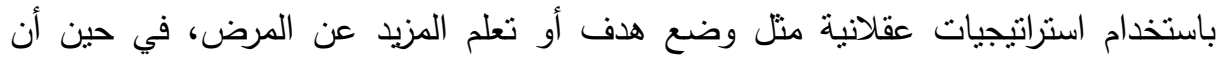

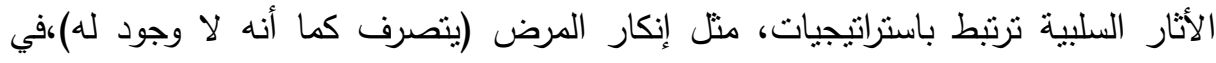

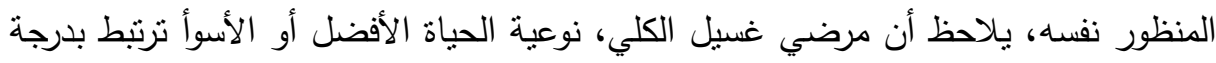

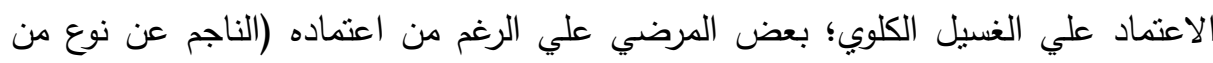

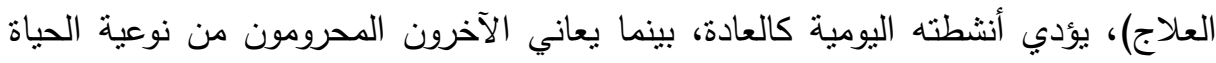

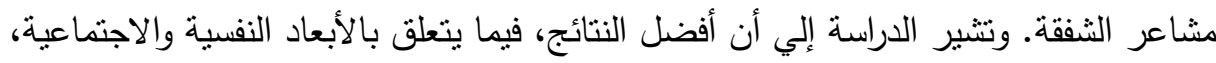
تتعلق بالاعتقاد بعلاج هذا القصور الكلوي المزمن عن طريق عملية زرع الكلي.

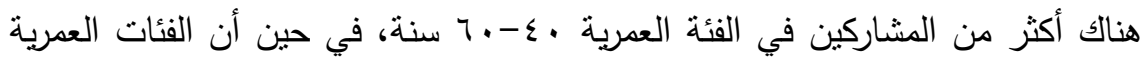

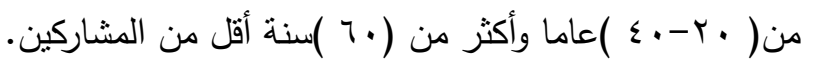




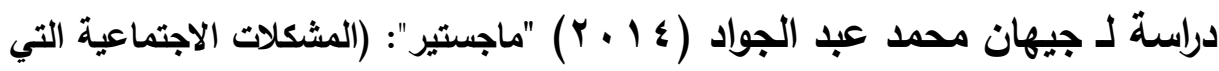
تواجه أسر مرضى الفثل الكلوي ودور طريقة خدمة الفرد في مواجهتها)

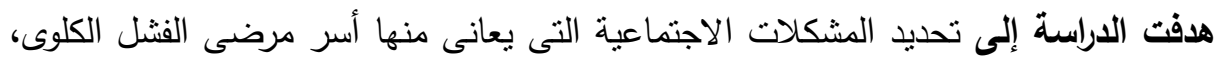
تحديد الخدمات التى يحتاجها مرضى الفشل الكلوى وأسرهم، تحديد الصعوبات التى التى تواجها

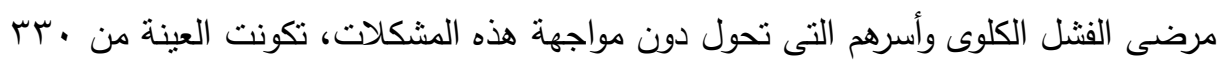

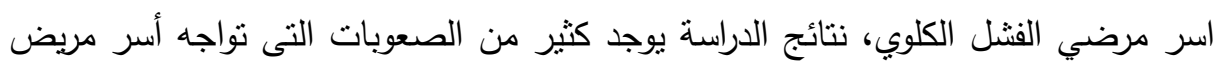

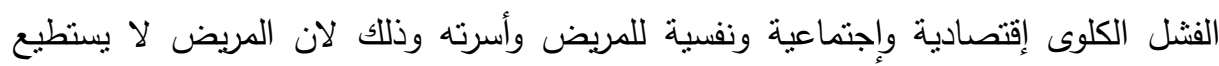

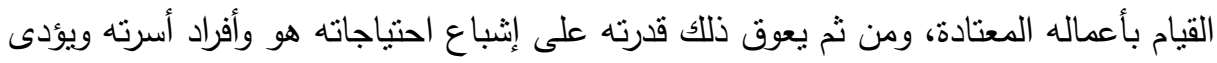

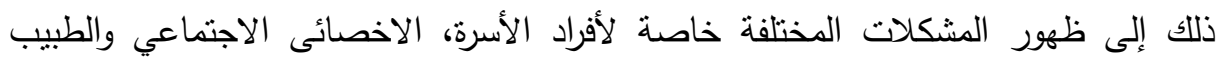

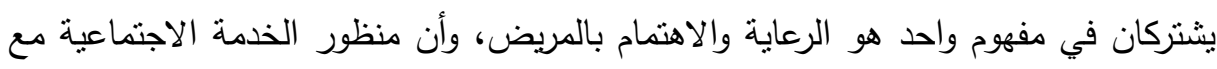
المرض جزء أساسي في علاج المرضى ومواجهة المشكلات التي يتعرضون لها.

\section{الإطار النظظيه}

النظريات(Fight Or Coping Syndrome) : نظرية أعراض المواجهة أو الهروب

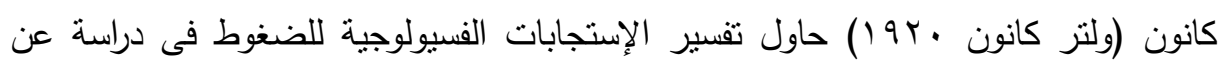

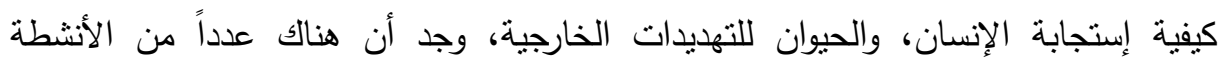

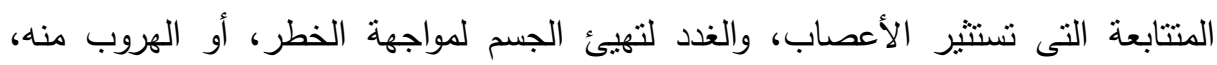

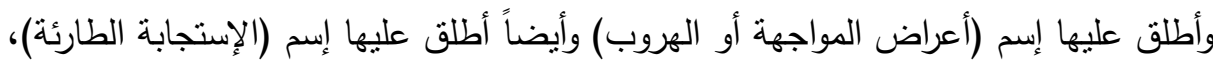

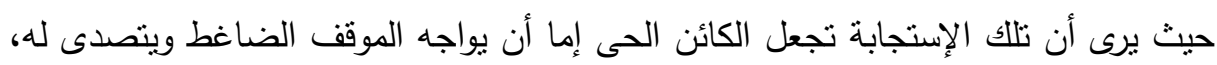
أو يتجنب ذلك الموقف ويهرب منه. (Zimbrado,1988,P,218) نظرية (إلياس وأخرون) "تظرية تغيير الحياة ": إستخدم (إلياس وأخرون) نظرية تغير

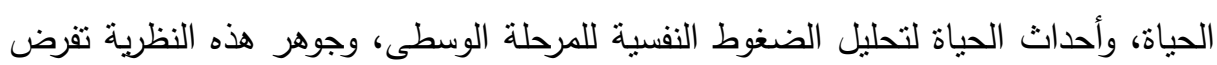

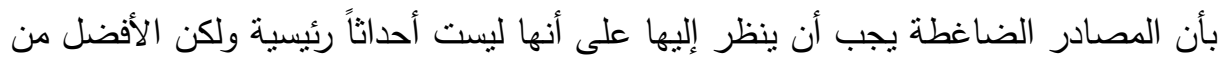


ذللك أنه يوجد مهام تتطلب (التكيف مع العمل) للسبطرة على أى تغير يحدث فى الحياة على الأقل فهناك خمس مهام رئيسية يجب أن نوجه:1- ضبط التعديل فى وصف الدور ، والسلوكيات المتوقعة. r- إعادة تقييم شخصية الفرد، تأييد المصادر الإجتماعية. r- إعادة تقييم الذات داخل شبكة العمل الإجتماعية. ع- إعادة تطور التقييم المعرفى اليومى للشخص، إعداده طبقاً للتفاعلات. ه- التحكم فى الضغوط التى نربط بها التوقعات غير الفعلية عن المواقف الكلية.

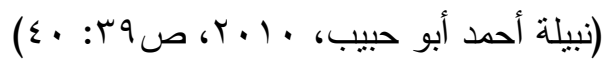

وظائف المواجهة: تصنف المجهودات والأنشطة التي يبذلها الفرد للتعامل مع مصدر المشكلة، والتخفيف من التوترات الإنفعالية المترتبة عليها إلى مجموعتين، يشار لها في أدبيات

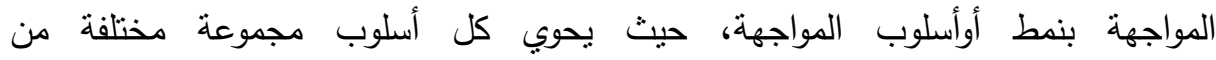

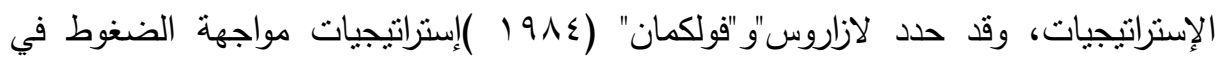
نوعين هما :المواجهة المتمركزة حول المشكلة:Coping centré sur le problème : هي عبارة عن الجهود النى يبذلها الفرد لتعديل العلاقة الفعلية بين الثخص والبيئة، فالثخص في المواقف الضاغطة يحاول تغيير أنماط سلوكه الثخصى أو يعدل الموقف ذاته، فيحاول تغيير لئن

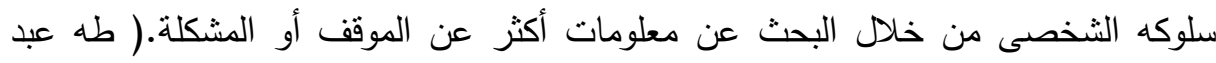

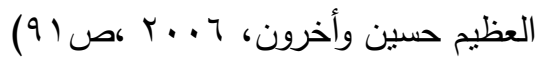
وهى الإستراتيجيات التى تقوم على: التقييم الإيجابي للموقف، إستخدام مهارات التخطيط، التقبل، إعادة البناء أو التشكيل الإيجابى للموقف، وغات والبـاً ما ترتبط هذه الإستراتيجيات بنتائج

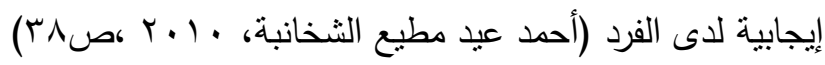

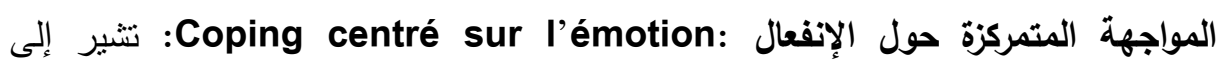
الجهود التى يبذلها الفرد لتتظيم الإنفعالات وخفض المشقة والضيق الإنفعالى الذى يسبيه الحدث أو الموقف الضاغط للفرد، عوضاً عن تغيير العلاقة بين الشخص والبيئة، وتتضمن: 
الإبتعاد، تجنب التفكير في الضواغط، الإنكار) · (طه عبد العظيم حسين وأخرون،

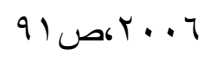

العلاقة بينهما : يشير "لازاروس"و "فولكمان" إلى أن كل من إستراتيجيات المواجهة المتركزة

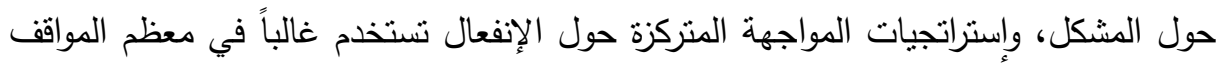
الضاغطة، وأنهما قد بسهل أو يعوق بعضهما بعضا ـ ـ (طه عبد العظيم حسين وأخرون، 9re T...T الفرق بين التكيف والتوافق:- تباينت آراء الباحثين في تحديد مفهومي التكيف والتوافق، فبعضهم أثنار إلى وجود فرق بين الدفهومين، ومنهم من إعتبرهما وجهان لعملة واحدة .

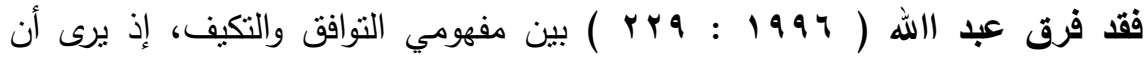

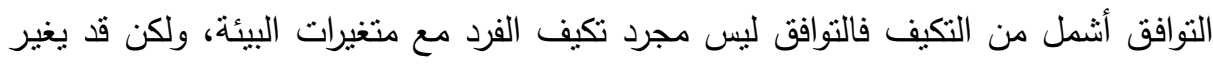
الإنسان ظروف بيئته لتلائمه، وذلك من خلال إعادة تتظيم الخبرة الشخصية، أومن خلا لالد إعادة تنظيم عناصر البيئة. أما مرحاب ( £191 : ب ) فيشير إلى أن مفهومي التوافق والتكيف بستخدمان

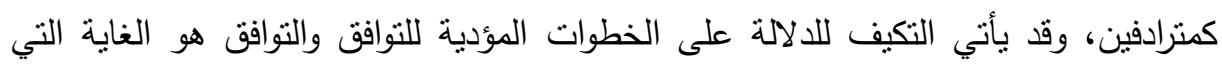

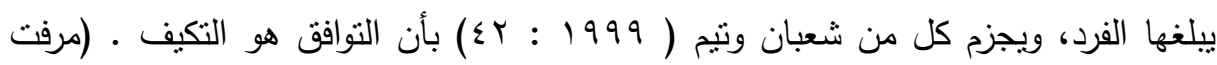

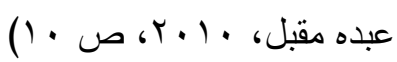
و نجد أيضاً من الباحثين من يخلط بين مفهوم التكيف ومفهوم التوافق فينظر إلى

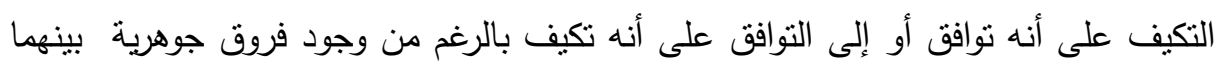

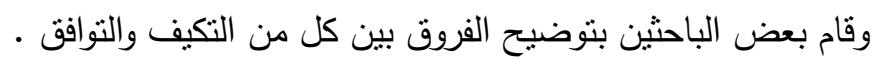

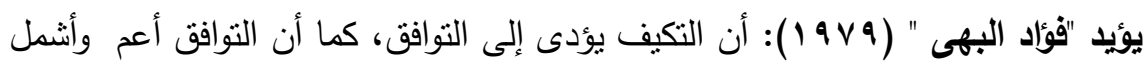

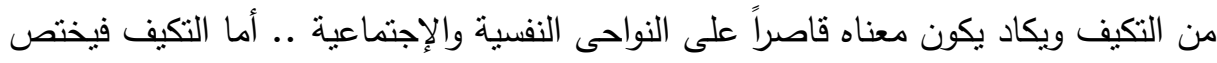

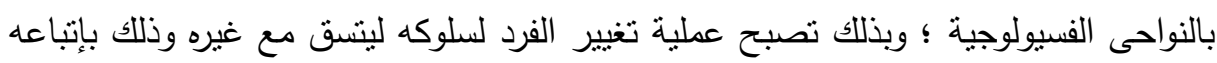

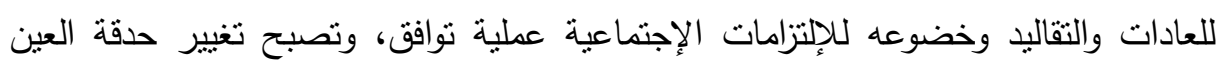

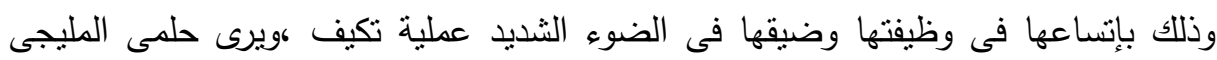

$$
\text { المجلد التاسع والثلاثون، الجزء الأول، سبتمبر V r. V }
$$




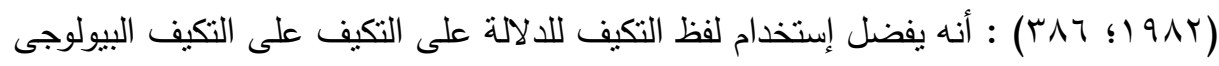

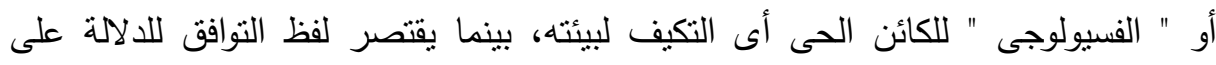

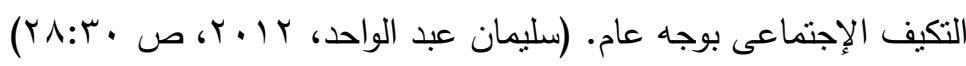

$$
\begin{aligned}
& \text { العوامل أو المتغيرات في أساليب التكيف هي: }
\end{aligned}
$$

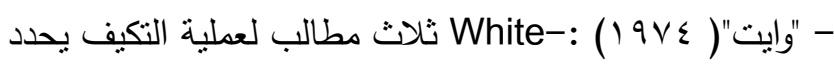
ل ل ل ل فهم الموقف الضاغط. ل ل إدراك الانفعالات وكيفية التعبير عنها في المواقف المناسبة. V حفظ الإحساس بالتكامل الثخصي، وتحقيق الضبط الذاتي للبيئة . (أحمد عيد مطيع

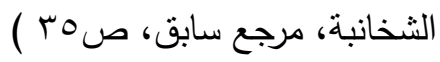

$$
\begin{aligned}
& \text { ومن أهم سمات وخصائص الأسرة: }
\end{aligned}
$$

ا ـ أول خلية يتكون منها البيان الإجتماعي هي الأسرة، وهى أكثر النظم الإجتماعية عمومية

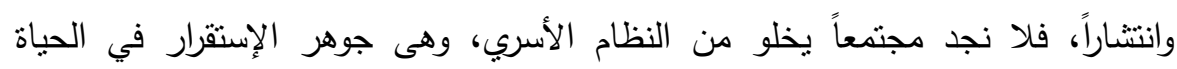

$$
\text { الإجتماعية. }
$$

r. عادة ما ينتظم أعضاء الأسرة في مكان واحد للمعيشة ويقيمون في بيت واحد، وقد يتخذ

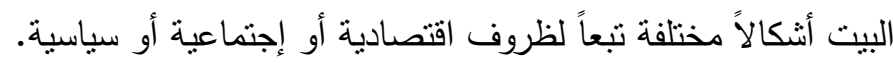

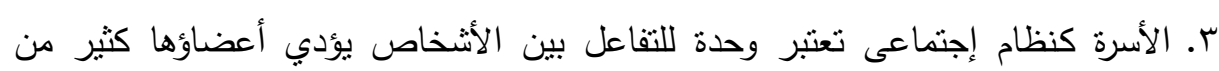

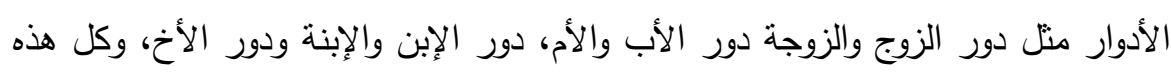

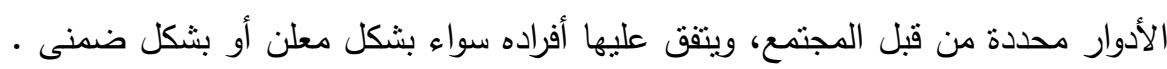

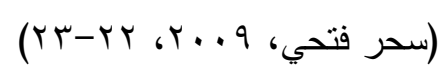

ع. تقوم الأسرة على أوضاع ومصطلحات يقرها المتمع، ويفرض على الأفراد مسايرتها والإلتزام بها، ومن يخرج على ذلك يقاتله المجتمع ويفرض على عليه عقوبات.

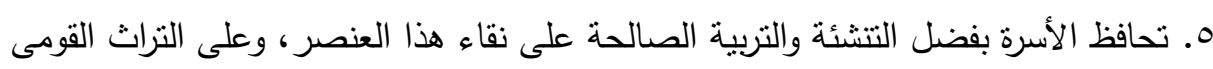
والحضاري. 
7. الأسرة هى الإطار العام الذى يحدد تصرفات أفرادها ، فهى التى نتكل حياتهم وتصفي

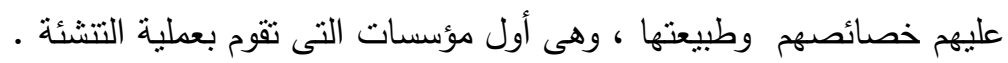
V. توفر الأسرة لأعضائها الأساس العاطفى الذى يوفر الإستقرار والأمن. (هدى فناوى،

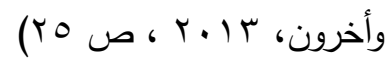

\section{إلجراعايه اللهمه}

تعد هذه الدراسة من الدراسات الوصفية والتى تقوم على تقدير خصائص ظاهرة معينة أو موقف معين تغلب عليه صفة التحديد وتعتمد على جمع الحقائق وتحليلها وتفسيره الإستخلاص دلالتها وتصل بذلك لإصدار التعميمات بشأن المواقف أو الظاهرة موضوع

الاراسة الوصفية: هى دراسة تتخيصية تقوم بتحديد الظاهرة كماً وكيفاً، وعلى مستوى الحاضر والماضى القريب أيضاً بما يحقق المعرغة الكاملة عن أبعاد الموقف المراد دراسته

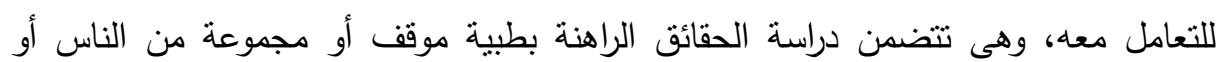

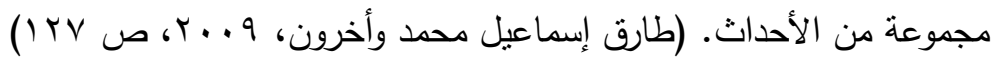

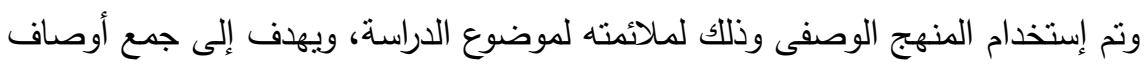
كمية وكيفية عن الظاهرة المدروسة كما تحدث فى وضعها الطبيعى، وذلك من أجل توضيح العوامل المتسبية فيها والنتائج المترتبة عليها، حيث هدفت الدراسة إلى التواصل لأنسب حلول

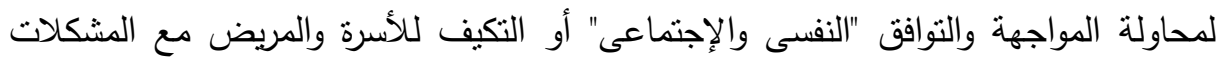
البيئية المصاحبة لطرق علاج مرض الفثل الكلوى المزمن.

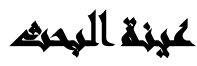

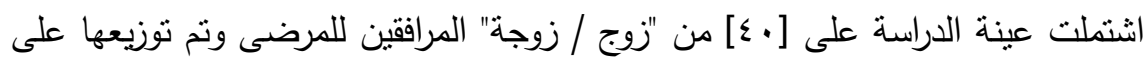

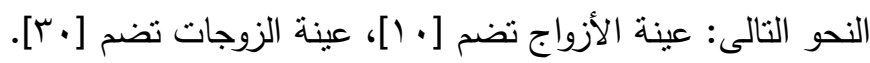

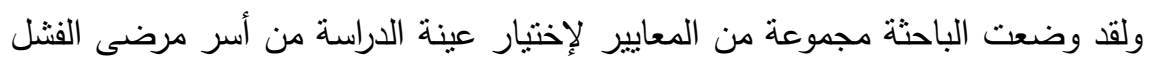
الكلوى المزمن وتوضح على الأسس التالية:

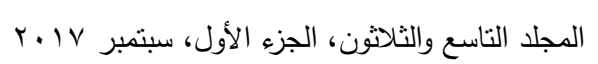


- أن تكون عينة الدراسة لأسر المرضي وبالأخص الزوج / الزوجة المرافق مع المريض.

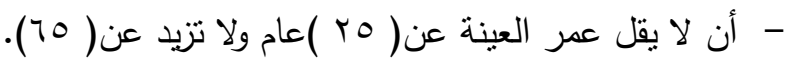

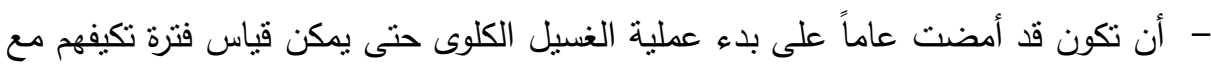

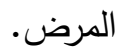

\section{أوايت الهمبه}

- صحيفة مقابلة عن البيانات الأولية مطورة حيث قامت الباحثة بنطويرها. - مقياس للمواجهة ( إعداد الباحثون). - مقياس للتكيف ( إعداد الباحثُن).

كلا من المقياسين السابقين تم من خلالهم قياس ثلاث أبعاد وهو البعد [النفسى -

$$
\text { الإجنماعى - البيئى]، ولكل بُعد ( • r )عبارة. }
$$

- - مقياس المواجهة: تصف عبارات مقياس المواجهة للأسرة من حيث النواحي النفسية والإجتماعية والبيئية التى تواجه مريض الفشل الكلوى الذى يعلاج بغسيل الكلى الغسيل

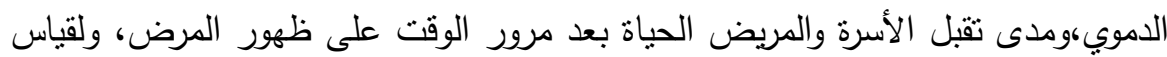

الثلاث الأبعاد نحدد (•r) عبارة لكل منهم بحيث يكون مجمل المقياس( • ؟) عبارة. ثبات مقياس المواجهة: للتحقق من ثنات الاختبار استخدمت الباحثة معادلة ألفا كرونباخ

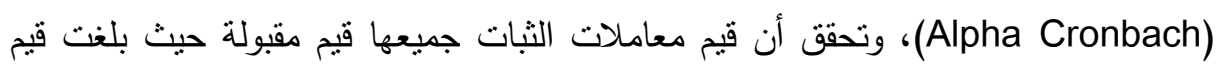

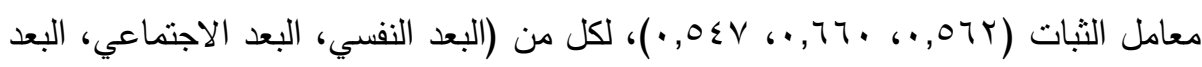

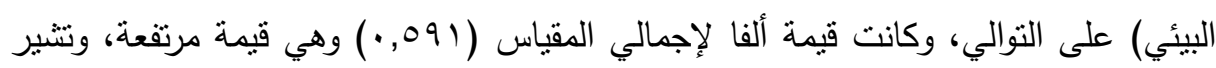
هذه القيم من معاملات الثبات إلى صلاحية المقياس للتطبيق وإمكانية الاعتماد على نتائجه

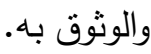

صدق المقياس: نم حساب معاملات ارتباط كل بعد من أبعاد الاختبار بالارجة الكلية

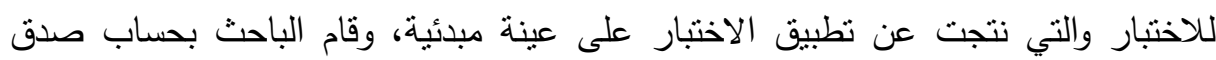
الإتساق الداخلي ومعامل الارتباط المصحح كالآتي: 
صدق الاتساق الداخلي السابق للاختبار نجد أن معامل ارتباط أبعاد المقياس دالة معنوياً

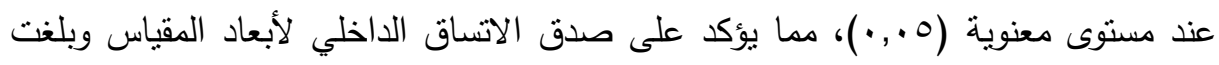

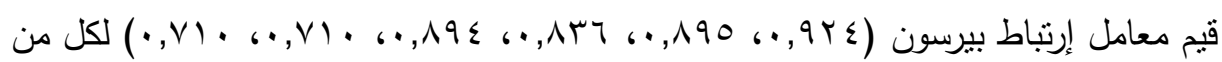

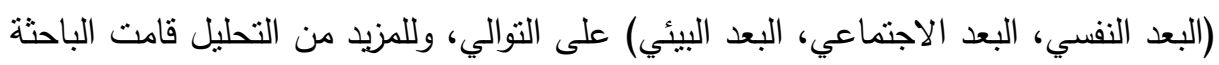

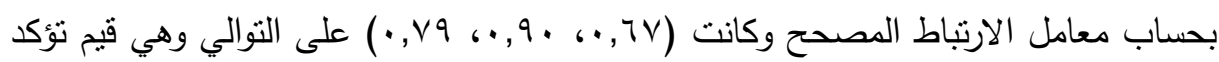
على صدق المقياس.

r- مقياس التكيف: تصف عبارات مقياس التكيف للأسرة من حيث النواحي النفسية والإجنماعية والبيئية التى تواجه مريض الفنشل الكلوى الذى يعلاج بغسيل الكلى الغسيل

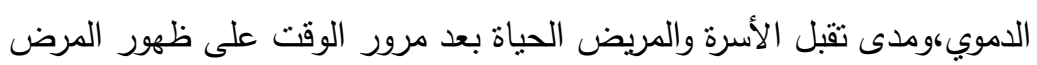
ثبات مقياس التكيف: للتحقق من ثبات الاختبار استخدمت الباحثة معادلة ألفا كرونباخ التبن

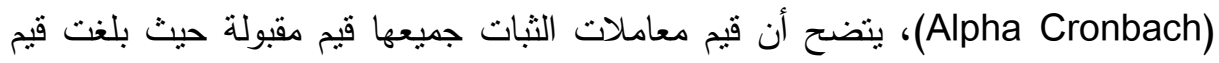

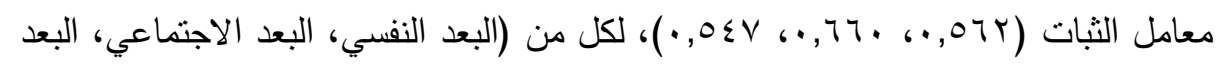

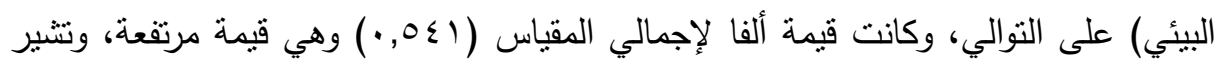
هذه القيم من معاملات الثبات إلى صلاحية المقياس للتطبيق وإمكانية الاعتماد على نتائجه والوثوق به ولقياس الثلاث الأبعاد نحدد (·r) عبارة لكل منهم بحيث يكون مجمل

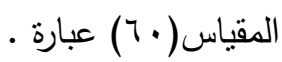

صدق المقياس: نم حساب معاملات ارتباط كل بعد من أبعاد الاختبار بالدرجة الكلية

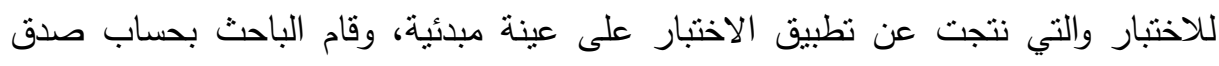

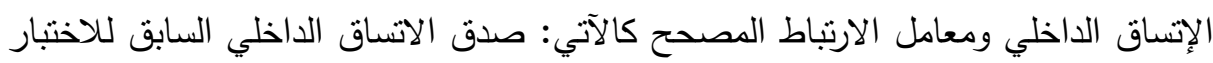

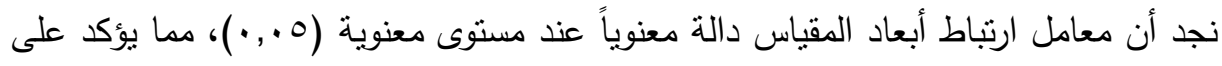

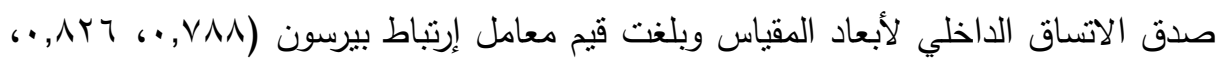
rT7

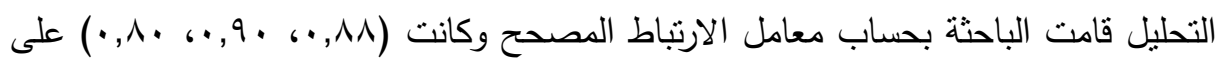
التوالي وهي قيم تؤكد على صدق المقياس. 


\section{مجالايش اللهمه}

المجال المكانى: تم إجراء الدراسة الميدانية بمستشفيات عديدة حيث قامت الباحثة بزيارة بعض المستشفيات الحكومية والتى منها: [مستشفى الحسين - مسنشفى الدمرداش - مستشفى سيد جلال " باب الثعرية "]. وقامت الباحثة بزيارة مستشفى تابعة للأعمال الخيرية وهى خميسى التخصصى بمدينة العاشر من رمضان.

المجال البشرى: تمنلت العينة للاراسة من عينتين الأولى تكونت من الأزواج (• ()، أما الثانية فتكونت من (•r) زوجة من المرافقين للمريض. المجال الزمنى: إستغرقت هذه الدراسة حوالى عامين تقريباً ومرت بالمراحل التالية:

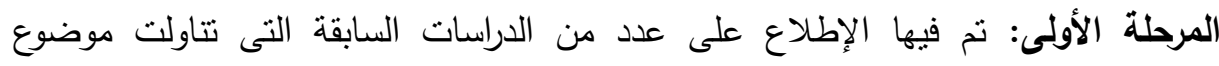

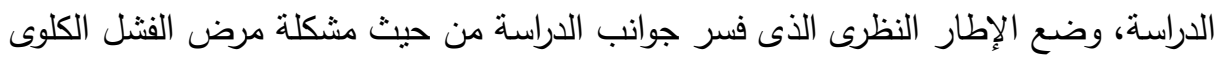

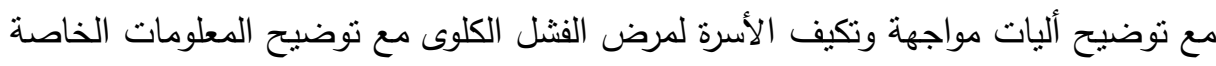
به والتعرف على أسباب ظهوره وطرق علاجه. المرحلة الثانية: تجهيز أدوات الدراسة وعرض المقياس على المحكمين والخبراء وعمل تقنين للإختبارات (الصدق والثبات) للمقاييس.

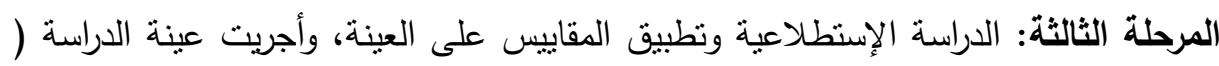

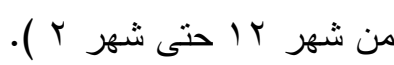
المرحلة الرابعة: تفريغ البيانات وتحليل النتائج ووضع النوصيات.

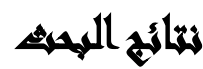

التحقق من صحة فروض الاراسة:

الفرض الأول: ينص على توجد علاقة ارتباطية دالة في البعد النفسي بين التكيف ومواجهة الضغوط. 
جدول(1): العلاقة الارتباطية في البعد النفسي بين التكيف ومواجهة الضغوط

\begin{tabular}{|c|c|c|c|c|c|c|}
\hline \multicolumn{2}{|c|}{ إجمالى العينة } & \multicolumn{2}{|c|}{ الزوجة (ن= · · r) } & \multicolumn{2}{|c|}{ الزوج (ن= - 1 ) } & \multirow{2}{*}{ أبعاد } \\
\hline المنالة & معامل ارتباط بيرنون & المعنوية & معامل ارتباط & المعنوية & معامل ارتباط & \\
\hline .,Y,7 & $\cdot ., Y$ & $\cdot, \cdot, r$ & *., हा। & •, § & $\cdot, r \vee q-$ & البعد النفسى \\
\hline
\end{tabular}

من الجدول السابق لنتائج العلاقة ارتباطية في البعد النفسي بين التكيف ومواجهة الضغوط إتضح التالي: من الجدول

- توجد علاقة ذات ارتباط دالة عند مستوى معنوية (0. . •) لعينة الزوجة في البعد النفسي

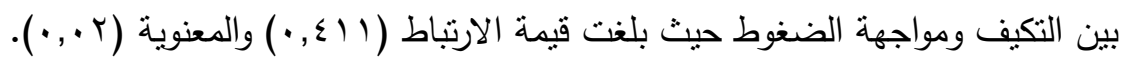

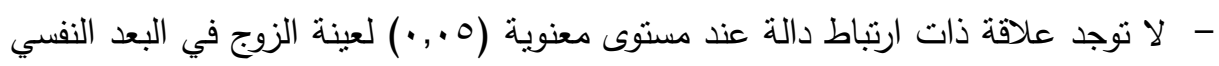
بين التكيف ومواجهة الضغوط. - لا توجد علاقة ذات ارتباط دالة عند مستوى معنوية (0., •) لإجمالي العينة في البعد النفسي بين التكيف ومواجهة الضغوط. مما سبق إتضح تحقق صحة الفرض: نوجد علاقة ارتباطية دالة في البعد النفسي بين التكيف ومواجهة الضغوط بالنسبة لعينة الزوجة.

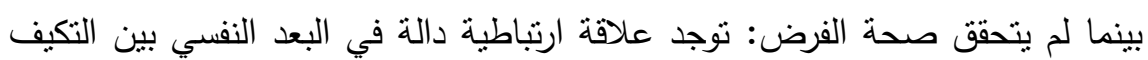
ومواجهة الضغوط لعينة الزوج وإجمالي العينة. من نتائج الفرض الأول: توجد علاقة ارتباطية دالة في البعد النفسي بين التكيف ومواجهة الضغوط.

تنين وجود علاقة إرتباطية في البعد النفسي بين التكيف ومواجهة الضغوط بالنسبة لعينة الزوجة ويرجع ذلك إلى أن الزوجة أكثر تأثيراً من الزوج فالزوجات بصفة إندان عامة لديهم شعور

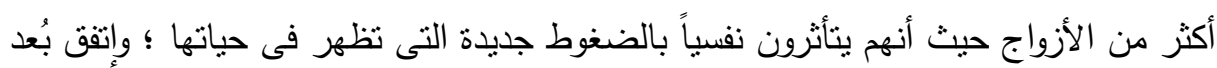

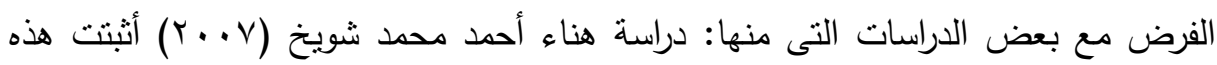
الدراسة أن هناك فروف بين أليات المواجهة والمتغيرات النفسية الجديدة لنوعية الحياة وهذا لهاء ظهر من خلال عينة الدراسة حيث قامت الباحثة بعمل برنامج تدريبى يقيس المتغيرات النفسية

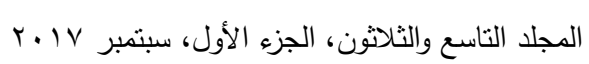


والفسيولوجية لنوعية الحياة بين مجموعتين ضابطة وتجريبية واثبتت أن هناك فروق بينهم وهذا يدل على أن مواجهة المتغيرات النفسية تساعد تحسين نواحى الحياة، ومن المنبت من خلال هذه الدراسة أن الحالة النفسية للأسرة تأثر على مريض.

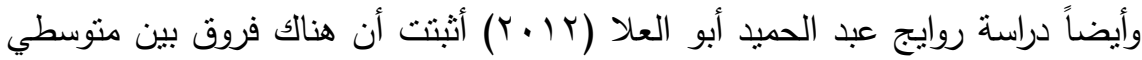
درجات المجموعة التجريبية في القياسين قبل وبعد تطبيق إجراءات البرنامج على مقياس الثعور بالوحدة النفسية في إتجاه القياس البعدي ؛ وأوضحت أيضاً دراسة نهال عبد الحميد

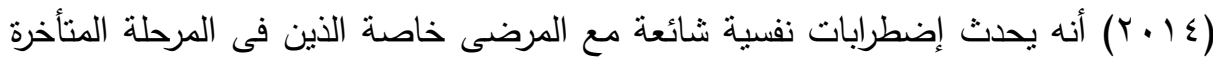

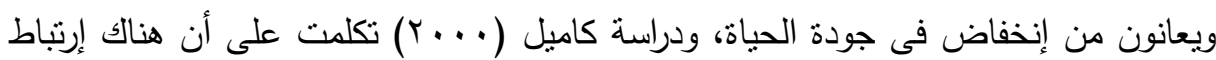
بين المستويات المرتفعة من الإكتئاب لدى المرضى الذين يعالجون بالغسيل الدموى وزيادة

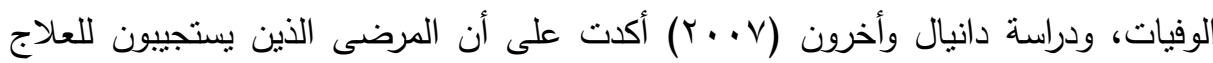

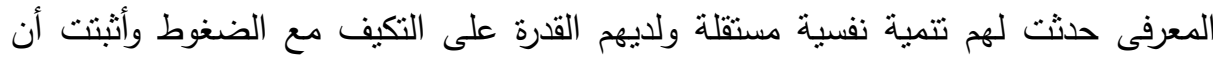

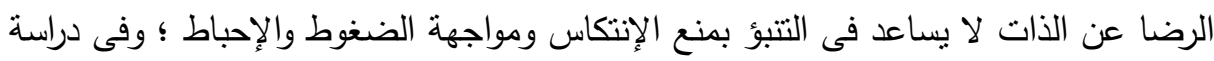

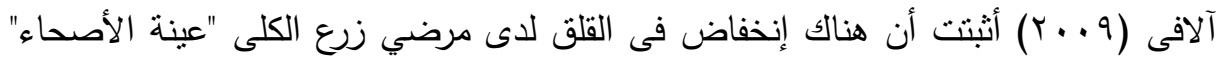
عن مرضى الغسيل الكلوى المزمن وهذا بعد عمل مقارنة بينهم ،ومن دراسة فان مانن

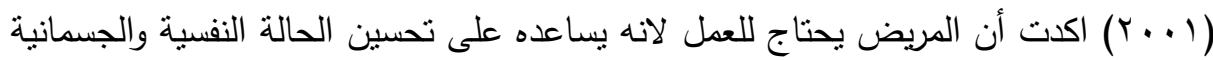
وهذا خاصة فى أول فترة من ظهور المرض. ومن ملخص الاراسات السابقة فقد إتضح لنا أن الحالة النفسية للمريض والأسرة تؤثز على فئ

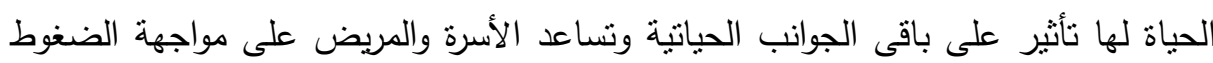

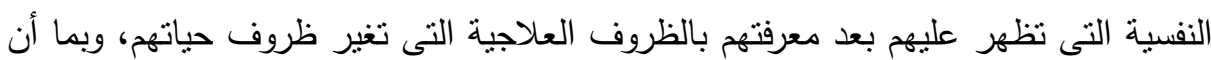

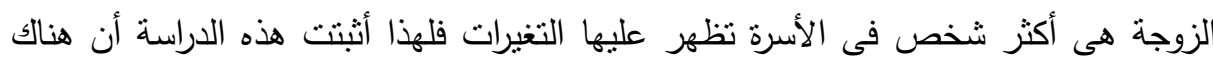

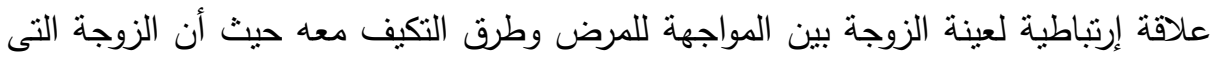
تتقبل فكرة المرض بصدمة بسيطة نساعدها على تقبل والتكيف مع المرض على العكس عندما ترفض فكرة المرض خوفاً من المستقبل ومن المشكلات التى تقع عليها فهذا يؤدى لعدم تكيفها 
وإتققت مع النظريات التالية التى تكلمت عن مواجهة الضغوط وتساعد الزوجة على تقبل الحالة الإنفعالية لها ومنها: نظرية هانز سيلى "الضغط النفسي" إستجابة الفرد فسيولوجية

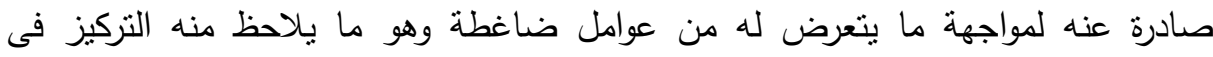

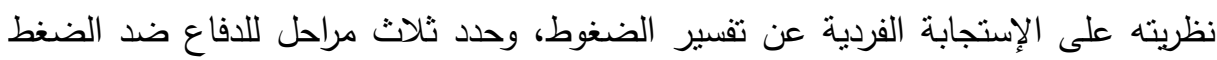
وهى تمثل مراحل التكيف العام الضغوط، وحدد ثناث مراحل للدفاع ضد الضغط وهيه تمثل

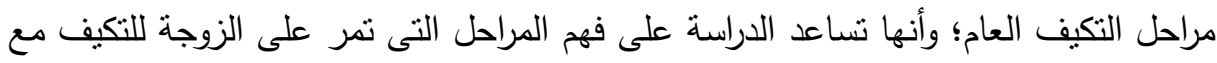

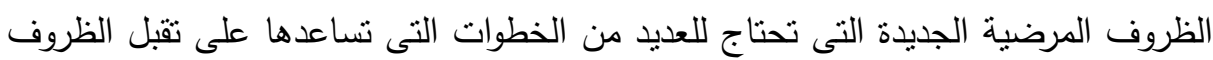
المختلفة التى تحدث للمريض وللأسرة؛ نظرية (إلياس وأخرون ) "نظرية تغيير الحياة " هذه النظرية تقيد فرض الدراسة فى تغير أحداث الحياة ووضع خطة لمعرفة المصادر الضاغطة نظيه التى يجب أن ينظر إليها على أنها ليست أحداث رشيدة ومحاولة التكيف معها وللسبطرة على فئى هذه التغيرات.

لم يتحقق صحة الفرض لدى عينة الزوج حيث لا نوجد علاقة إرتباطية في البعد النفسي

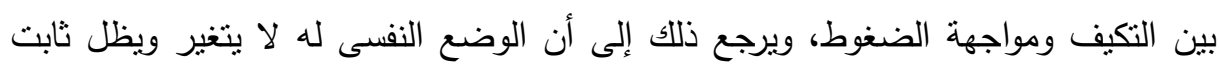

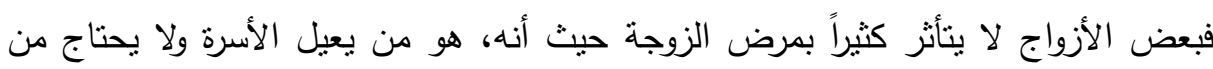

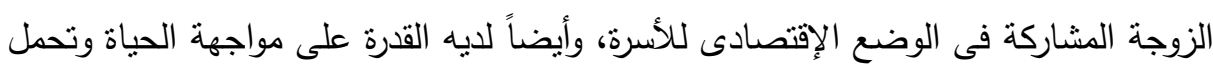

$$
\text { المشكلات الجديدة التى نظهر عليه. }
$$

الفرض الثاني: ينص على أن توجد علاقة ارتباطية دالة في البعد الاجتماعي بين التكيف

$$
\text { ومواجهة الضغوط. }
$$

\begin{tabular}{|c|c|c|c|c|c|c|}
\hline \multicolumn{2}{|c|}{ إجمالى العينة (ن = ـ ع) } & \multicolumn{2}{|c|}{ 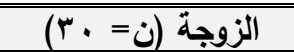 } & \multicolumn{2}{|c|}{ الزوج (ن= - 1 (1) } & \multirow[b]{2}{*}{ أبعاد } \\
\hline المعنوية & معامل ارتباط بيرسون & الدعنوية & معامل ارتباط بيرسون & المعنوية & معامل ارتباط بيرسون & \\
\hline$\cdot, 7$ & $\cdot, \cdot \wedge \varepsilon$ & $\cdot, \Gamma$ & $\cdot, I \vee V$ & $\cdot, 7$ & $\cdot, 1 \wedge \varepsilon-$ & لاجتماعي \\
\hline
\end{tabular}

جدول(ץ): العلاقة الارتباطية في البعد الاجتماعي بين التكيف ومواجهة الضغوط

من الجدول السابق لنتائج العلاقة ارتباطية في البعد الإجتماعى بين التكيف ومواجهة

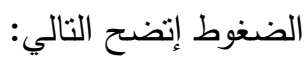


- لا توجد علاقة ذات ارتباط دالة عند مسنوى معنوية (0., •) لعينة الزوجة في البعد الإجتماعى بين التكيف ومواجهة الضغوط. - لا توجد علاقة ذات ارتباط دالة عند مستوى معنوية (0.,.•) لعينة الزوج في البعد الإجتماعى بين التكيف ومواجهة الضغوط. - لا توجد علاقة ذات ارتباط دالة عند مستوى معنوية (0., •) لإجمالي العينة في البعد الإجتماعى بين التكيف ومواجهة الضغوط.

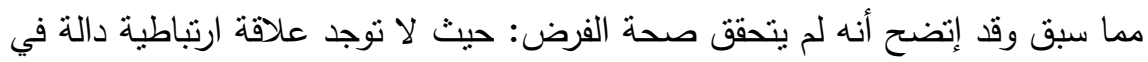
البعد الإجتماعى بين التكيف ومواجهة الضغوط لعينة الزوجة ولعينة الزوج وإجمالي العينة. فتتبين عدم وجود علاقة إرتباطبة لعينة الزوجة فى البعد الإجتماعى بين المواجهة

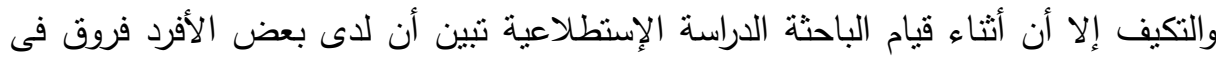

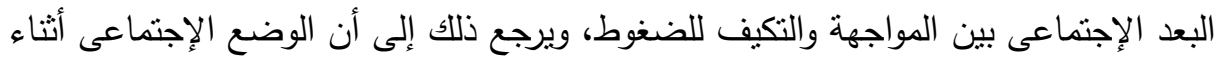
مواجهة الزوجة مرض زوجها فإن وضعها الإجتماعى بين العائلة والأصدقاء يكون لله دوراً

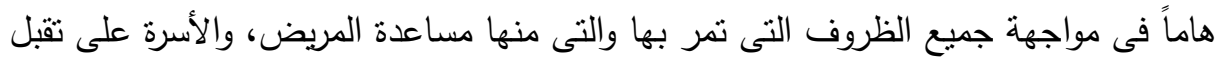

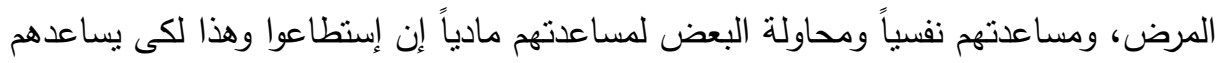

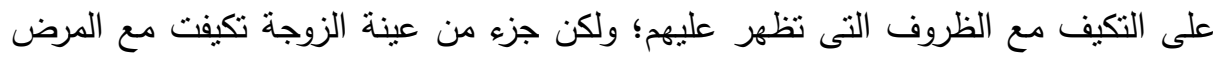

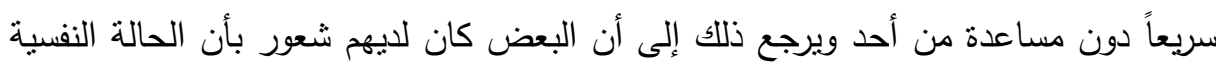

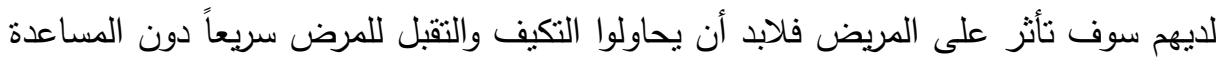

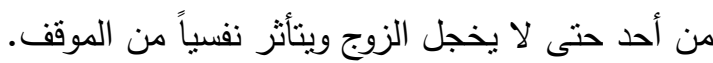
تبين عدم وجود علاقة ارتباطية أيضاً لعينة الزوج فى البعد الإجتماعى بين التين المواجهة

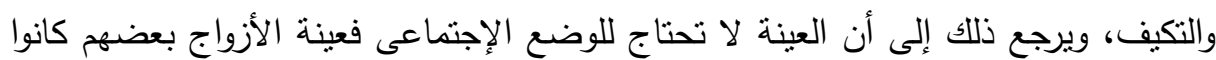

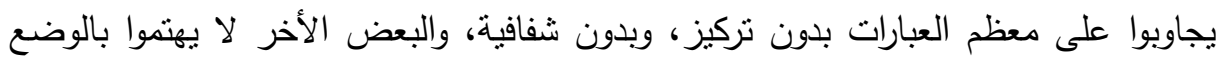

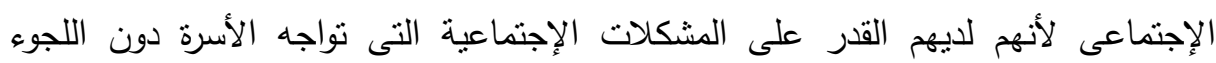
لمساعدة من المحيط بهم. 
الفرض الثالث : توجد فروق ذات دلالة إحصائية بين الأزواج والزوجات فى الميكانيزم النفسى والاجتماعى والبيئى لمواجهة الضغوط. جدول(r): يوضح نتائج اختبار (ت) للفروق بين الأزواج والزوجات في الميكانيزم النفسى والاجنماعى والبيئى لمواجهة الضغوط لهابر

\begin{tabular}{|c|c|c|c|c|c|c|}
\hline المعنوية & قيمة ت & المُعيارى & المتوسط & العدد & العينة & أبعاد المقياس \\
\hline \multirow[b]{2}{*}{$\cdot, \cdots$} & \multirow{2}{*}{$r, 97 r$} & $\bar{r} r, r$ & $0 V, q$ & 1. & الزوج & \multirow[b]{2}{*}{ البعد النفسى } \\
\hline & & 7,1 & $7 r, 9$ & $r$. & الزوجة & \\
\hline \multirow[b]{2}{*}{$\cdot, \cdot 7$} & \multirow{2}{*}{ 1,9ז } & $\overline{V, 1}$ & 79,1 & 1. & الزوج & \multirow{2}{*}{ البعد الاجتماعى } \\
\hline & & $7, Y$ & $V \mu, T r$ & $r$. & الزوجة & \\
\hline \multirow{2}{*}{$\cdot, .9$} & \multirow{2}{*}{ 1,Vדr } & $7, \wedge$ & 09,0 & $1 \cdot$ & الزوج & \multirow{2}{*}{ البعد البيئى } \\
\hline & & $0, \mathrm{~V}$ & $\pi r, r v$ & $\Gamma$. & الزوجة & \\
\hline \multirow{2}{*}{$\cdot, \cdots r$} & \multirow{2}{*}{$\Gamma, 1 \wedge \vee$} & 9,1 & $1 \wedge 7,0$ & 1. & الزوجـ & \multirow{2}{*}{ إجمالى مقياس المواجهة } \\
\hline & & $1 \Gamma, 1$ & $r \cdots, q$ & $r$. & الزوجة & \\
\hline
\end{tabular}
اتضح من الجدول السابق التالي: وجود فرق ذو دلالة معنوية بين عينة الدراسة تبعاً لمتغير عينة الدراسة (زوج/زوجة) لبعد البدان النفسي حيث بلغت قيم (ت) المحسوبة (Y,97Y) وهي أكبر من قيمة (ت) (ت) الجدولية

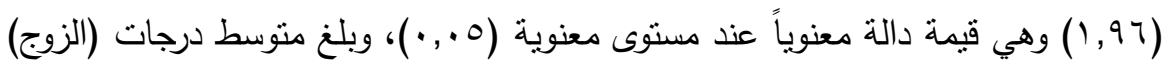

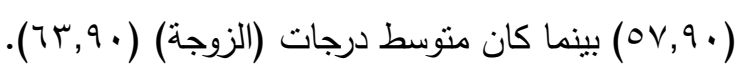

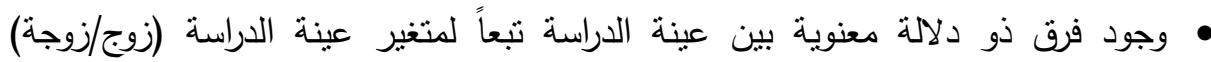

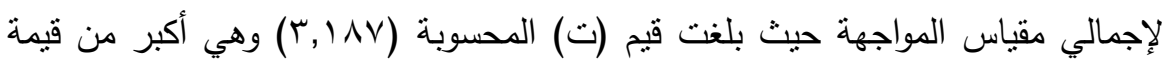

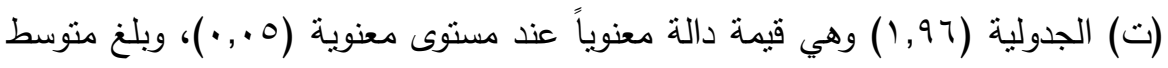

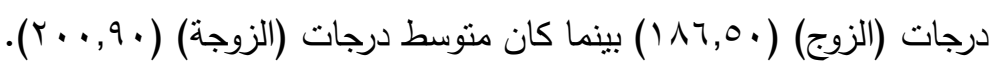

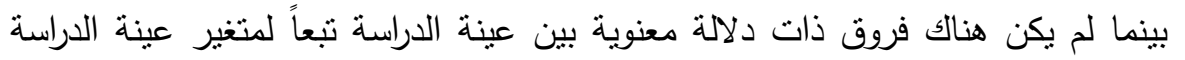
(زوج/زوجة) لباقي أبعاد المقياس حيث بلغت قيم (ت) المحسوبة جميعها أقل من قيمة

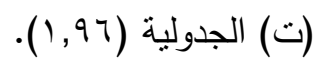


وتبين أن هناك فروق بين الأزواج والزوجات فى ميكانيزم البعد النفسى لمواجهة الضغوط

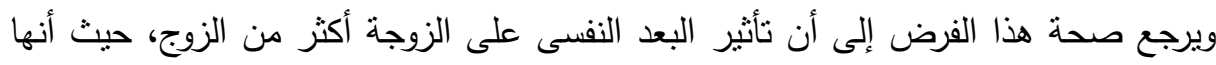

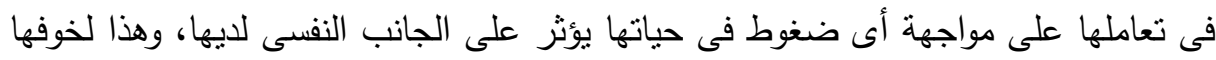

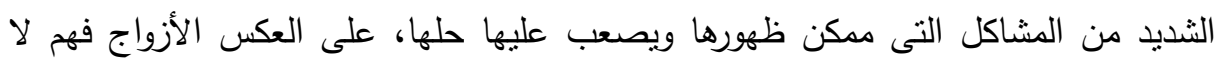

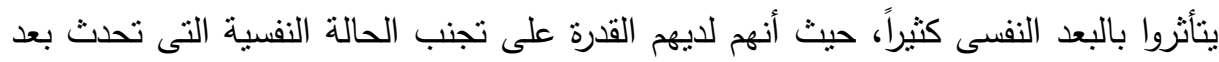

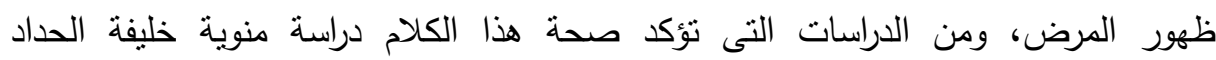

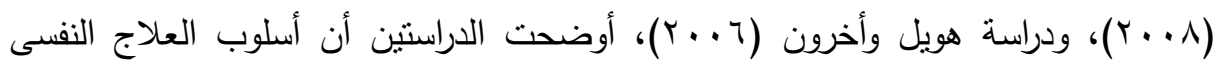

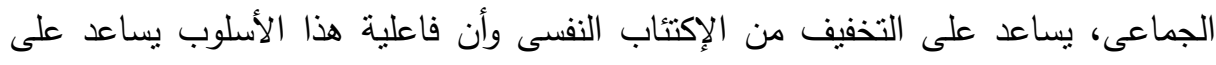
تحسين النواحى النفسية وعدم تعرض المرضى للإكتئاب الذى يؤثر على الأسرة بشكل يلاحظ الإنى

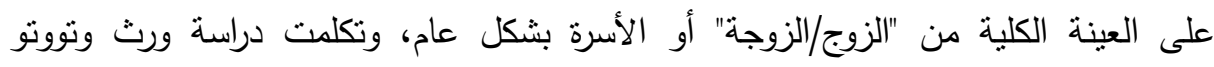

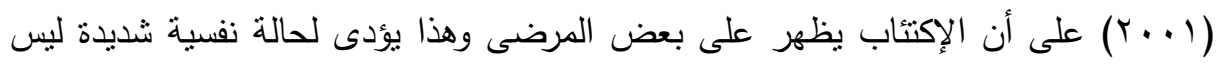

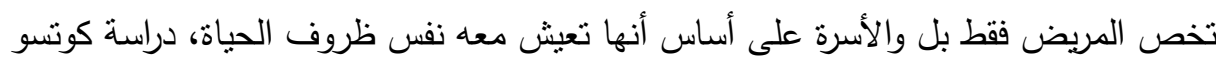

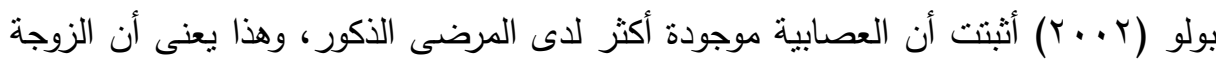

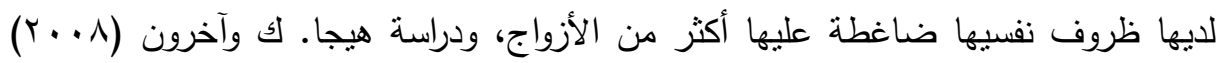
أشتارت إلى أن البعد النفسى حصل على أدنى الدرجات، وأثنتت أن تصورات الأفراد الفريدة عند نوعية الحياة تؤثر على مواجهة المرض. توجد فروق بين الأزواج والزوجات فى إجمالى الدقياس لمواجهة الضغوط صندة صحة الفرض

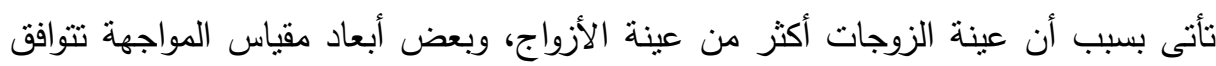

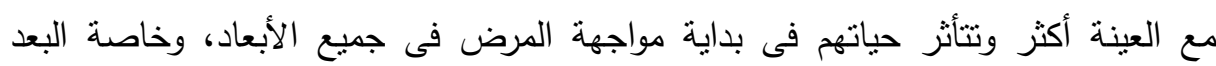

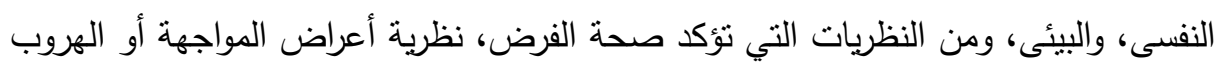

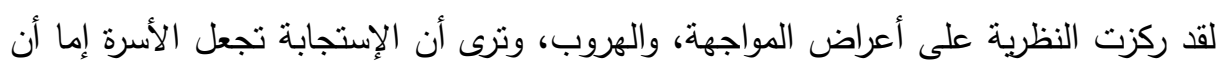
يواجه الضغط أو يهرب منه. لا توجد فروق بين الأزواج والزوجات فى البعد الإجتماعى لمواجهة الضغوط، لا توجد فروق لعينة الزوجة فى البعد الإجتماعى لمواجهة الضغوط إلا أن أثناء قيام الباحثة الدراسة 
الإستطلاعية وجود لدى بعض الأفراد، حيث أن معظم الزوجات الوضع الإجتماعى أثثاء

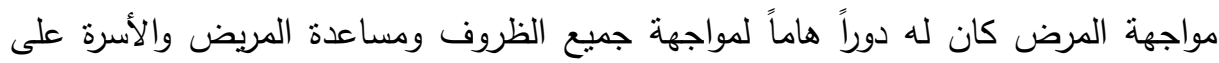

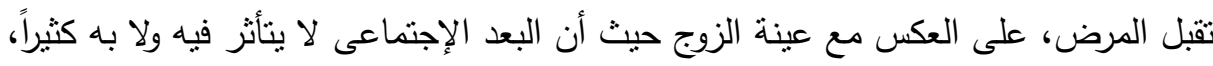

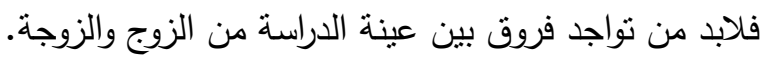

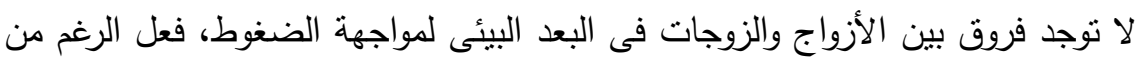

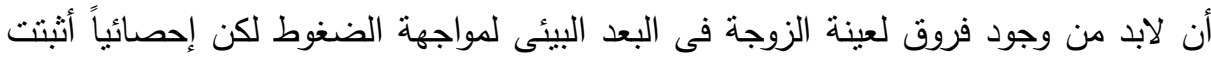

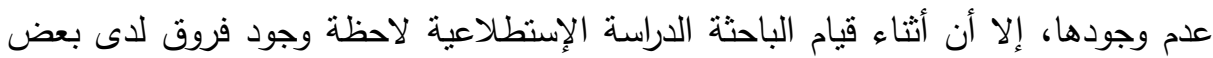

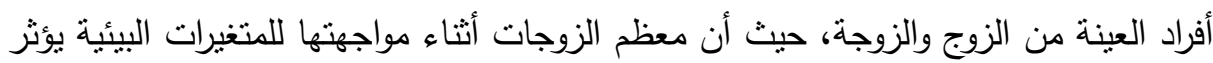

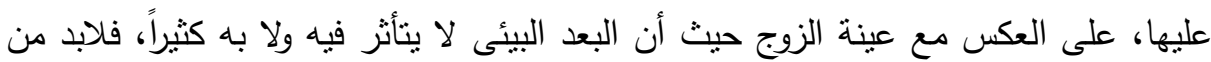
تواجد فروق بين عينة الدراسة من الزوج والزوجة.

\section{اللزوسيامي}

ا • ضرورة وجود أخصائى نفسى وإجتماعى خاص بوحدات غسيل الكلى لكى بساعد المرضى والأسرة على طرق المواجهة للمرض والتكيف معهد.

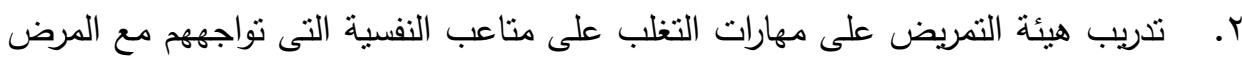
خاصة أن نسبية الوفيات فى نتزايد. r. إنشاء المزيد من وحدات غسيل الكلى حتى لا يضطر المريض لتحمل جهذ اضافي وتكلفة

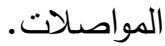

ع. عمل برامج إعلامية لتوعية المواطنين بكيفية المواجهة لمرض الفشل الكلوى، وكيفية الوقاية منه.

\section{zall}

أحمد زكى بدوى (7 (911): معجم مصطلحات العلوم الإجتماعية، بيروت، مكتبة لبنان.

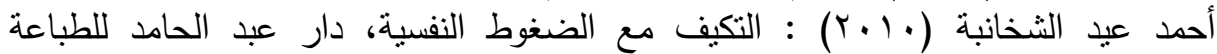

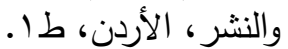




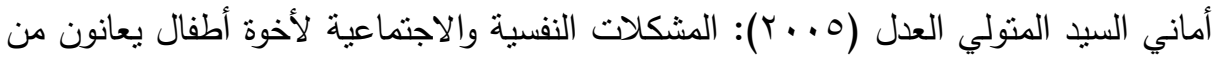

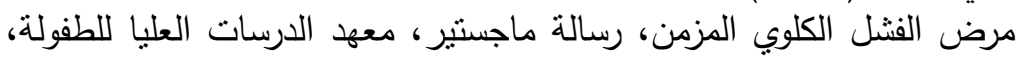
جامعة عين شمس.

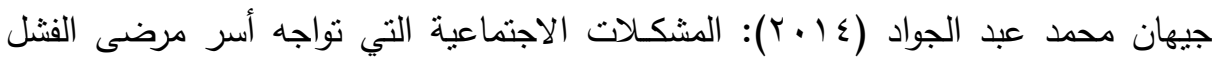
الكلوي ودور طريقة خدمة الفرد في مواجهتها، كلية الخدمة الاجتماعية، جامعة التهاتية

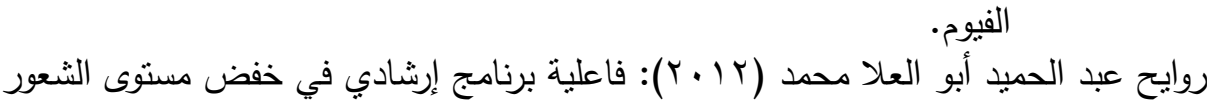

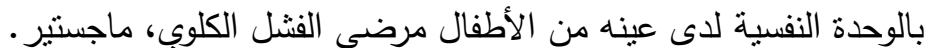

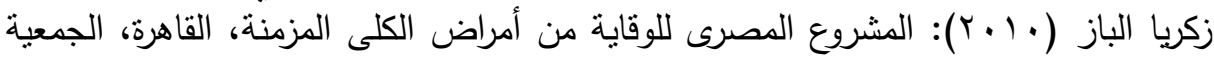

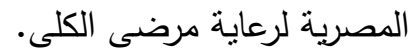

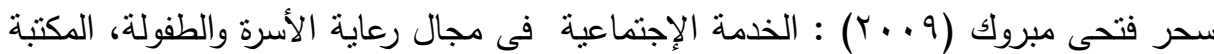

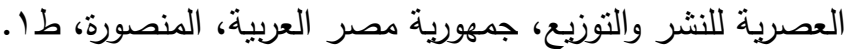

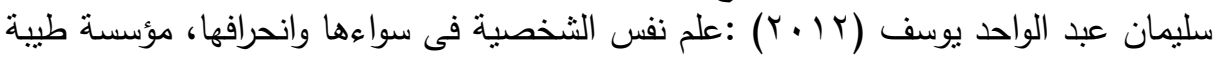

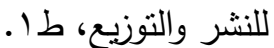

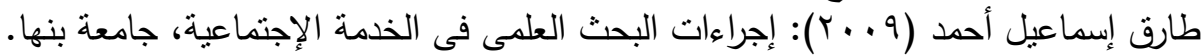

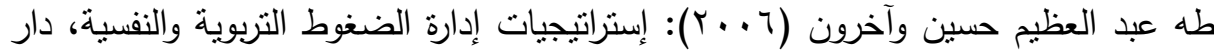

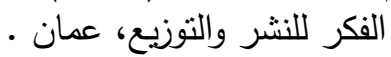

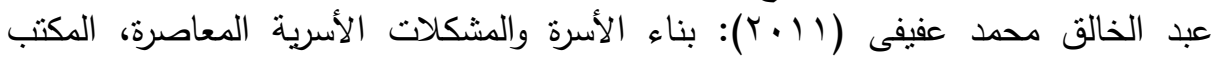
الجامعى الحديث، الإسكندرية.

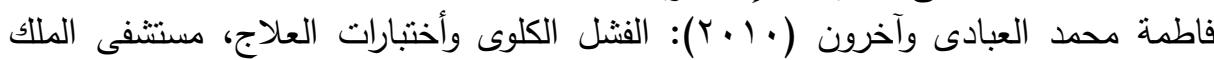

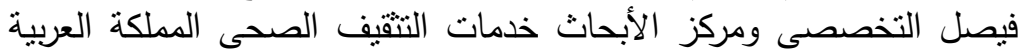
السعودية .

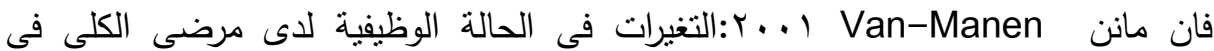
المرحلة النهائية خلال عامهم الأول من الغسيل

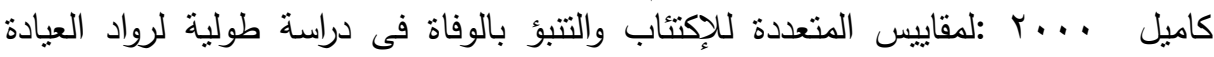
الخارجية من مرضى الفثل الكلوى المزمن

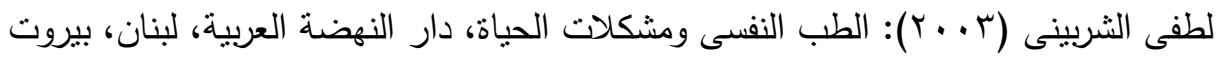

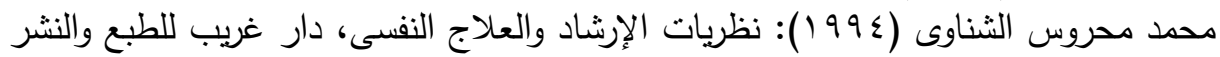

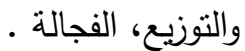

نهال محمد عبدالحمبد (ع ( ـ ب): الاضرابات النفسيه وجوده الحياه في مرضي الداء الكلوى في مراحله المتأخره، ماجسنتر ( الاضنرابات 
أحمد مصطفى العتيق وآخرون

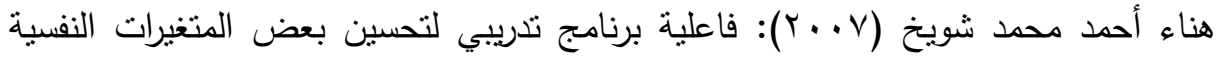

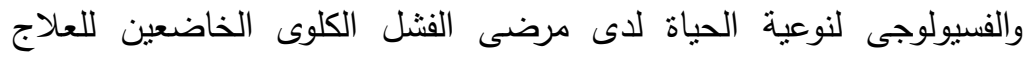
بالإستصفاء الدموى المتكرر ، دكتوراه

-Dictionnaire Hachette, maison de publier Hachette, Paris 2009.

-Higa, K., Kost, M., Soares, D., Morais, M., polins, B., (2008). Quality of life of patients with chronic renal insufficiency undergoing diayalis treatment. Acta Paulista de Enfermagem vol.21 no. spe Sao Paulo .

-Zimbrado, P,G, (1988) Psychology and Life, 12th ed Scott foresman company Boston.

\title{
IGHTING AND ADAPTATION MECHANISMS OF FAMILIES WITH KIDNEY FAILURE PATIENT
}

\author{
El-Atiq, A. M. ${ }^{(1)}$; Shoman, A. E. ${ }^{(2)}$; Hany, A. F. ${ }^{(1)}$
} and Sharwaida, Sara, S. A.

1) Institute of Environmental Studies \& Research, Ain Shams University. 2) Faculty of Medicine, Ain Shams University

\begin{abstract}
The current research aims to identify the methods of disease chronic kidney failure to the families of patients and how to cope with them, and the detection of differences between husbands and wives in both psychological and social dimension", "in the face of environmental pressures; where the sample consisted of 40 people from the families of patients with chronic kidney failure is divided into 10 pairs, 30, wife of researchers used a descriptive approach based on the scale of the confrontation, and the measurement of adaptation, as a means of serving the goal of the search results have reached.

Some of the most important there is a correlation function in the psychological dimension between adjustment and facing pressure for a sample of the wife, there is a correlation function in the psychological

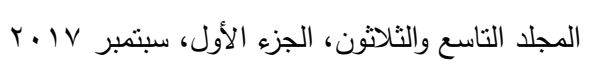


dimension between adjustment and facing pressure of a sample of the husband and the total sample, as recommended The researcher with a set of recommendations, the most important: need special psychological and social specialist dialysis units in order to help the patients and the family confrontation disease and adaptation, training of nursing skills and overcome the psychological troubles they face with the disease, especially that the comparative advantage of deaths is increasing, creating more dialysis units until the patient does not have to bear the extra effort and cost, transportation, the follow-up of chronic diseases that lead to kidney failure. 